\title{
Global Matrix 2.0: Report Card Grades on the Physical Activity of Children and Youth Comparing 38 Countries
}

\author{
Mark S. Tremblay, Joel D. Barnes, Silvia A. González, Peter T. Katzmarzyk, Vincent O. Onywera, \\ John J. Reilly, Grant R. Tomkinson, and the Global Matrix 2.0 Research Team
}

\begin{abstract}
The Active Healthy Kids Global Alliance organized the concurrent preparation of Report Cards on the physical activity of children and youth in 38 countries from 6 continents (representing $60 \%$ of the world's population). Nine common indicators were used (Overall Physical Activity, Organized Sport Participation, Active Play, Active Transportation, Sedentary Behavior, Family and Peers, School, Community and the Built Environment, and Government Strategies and Investments), and all Report Cards were generated through a harmonized development process and a standardized grading framework (from $A=$ excellent, to $F=$ failing). The 38 Report Cards were presented at the International Congress on Physical Activity and Public Health in Bangkok, Thailand on November 16, 2016. The consolidated findings are summarized in the form of a Global Matrix demonstrating substantial variation in grades both within and across countries. Countries that lead in certain indicators often lag in others. Average grades for both Overall Physical Activity and Sedentary Behavior around the world are $D$ (low/poor). In contrast, the average grade for indicators related to supports for physical activity was $C$. Lower-income countries generally had better grades on Overall Physical Activity, Active Transportation, and Sedentary Behaviors compared with higher-income countries, yet worse grades for supports from Family and Peers, Community and the Built Environment, and Government Strategies and Investments. Average grades for all indicators combined were highest (best) in Denmark, Slovenia, and the Netherlands. Many surveillance and research gaps were apparent, especially for the Active Play and Family and Peers indicators. International cooperation and cross-fertilization is encouraged to address existing challenges, understand underlying determinants, conceive innovative solutions, and mitigate the global childhood inactivity crisis. The paradox of higher physical activity and lower sedentary behavior in countries reporting poorer infrastructure, and lower physical activity and higher sedentary behavior in countries reporting better infrastructure, suggests that autonomy to play, travel, or chore requirements and/or fewer attractive sedentary pursuits, rather than infrastructure and structured activities, may facilitate higher levels of physical activity.
\end{abstract}

Keywords: international, play, policy, sedentary behavior, sport, active transportation

Recent systematic reviews confirm the extensive health benefits of regular physical activity for school-aged children and youth, ${ }^{1}$ as well as the harmful effects of excessive or uninterrupted sedentary behavior, especially screen time. ${ }^{2,3}$ Recent reports reinforce global public health concerns related to physical inactivity ${ }^{4-8}$ resulting in calls for more comprehensive, coordinated, and sustained efforts..$^{4,5,9}$ Yet global efforts to increase physical activity and decrease sedentary behaviors have been underway for years, and progress has

Tremblay and Barnes are with the Healthy Active Living and Obesity Research Group, Children's Hospital of Eastern Ontario Research Institute, Ottawa, Ontario, Canada. González is with the School of Medicine, Universidad de los Andes, Bogotá, Colombia. Katzmarzyk is with the Pennington Biomedical Research Center, Baton Rouge, LA, USA. Onywera is with the Dept of Recreation Management and Exercise Science, Kenyatta University, Nairobi, Kenya. Reilly is with the Physical Activity for Health Group, School of Psychological Sciences and Health, University of Strathclyde, Glasgow, Scotland. Tomkinson is with the Dept of Kinesiology and Public Health Education, University of North Dakota, Grand Forks, ND, USA; and the Alliance for Research in Exercise, Nutrition, and Activity, School of Health Sciences \& Sansom Institute for Health Research, University of South Australia, Adelaide, Australia. The Global Matrix 2.0 Research Team consists of Nicolas Aguilar-Farias (Universidad de La Frontera, Chile), Kingsley K. Akinroye (Nigerian Heart Foundation), Mohamed Ghaith Al-Kuwari (Aspetar Hospital, Qatar), Areekul Amornsriwatanakul (University of Western Australia), Salomé Aubert (Children's Hospital of Eastern Ontario Research Institute, Canada), Sarahjane Belton (Dublin City University, Ireland), Aleksandra Gołdys (University of Warsaw, Poland), Marianella Herrera-Cuenca (Central University of Venezuela), Justin Y. Jeon (Yonsei University, South Korea), Jaak Jürimäe (University of Tartu, Estonia), Tarun R. Katapally (University of Regina, Canada), Estelle V. Lambert (University of Cape Town, South Africa), Lisbeth R. Larsen (University College Lillebælt, Denmark), Yang Liu (Shanghai University of Sport, China), Marie Löf (Karolinska Institutet, Sweden), Tom Loney (United Arab Emirates University), Juan R. López y Taylor (Universidad de Guadalajara, México), Ralph Maddison (University of Auckland, New Zealand), Taru Manyanga (Children's Hospital of Eastern Ontario Research Institute, Canada), Shawnda A. Morrison (University of Primorska, Slovenia), Jorge Mota (Universidade do Porto, Portugal), Marie H. Murphy (Ulster University, Northern Ireland), Nelson Nardo Jr. (Universidade Estadual de Maringa, Brazil), Reginald T-A. Ocansey (Active Healthy Kids Ghana Group, Ghana), António Prista (Universidade Pedagógica, Mozambique), Blanca Roman-Viñas (Nutrition Research Foundation, Spain), Natasha K. Schranz (University of South Australia), Jan Seghers (KU Leuven, Belgium), Razinah Sharif (University Kebangsaan Malaysia), Martyn Standage (University of Bath, United Kingdom), Gareth Stratton (Swansea University, Wales), Tim Takken (Wilhelmina Children's Hospital, the Netherlands), Tuija H. Tammelin (LIKES Research Centre for Physical Activity and Health, Finland), Chiaki Tanaka (J.F. Oberlin University, Japan), Yan Tang (Shanghai University of Sport, China), and Stephen H. Wong (The Chinese University of Hong Kong, China). Tremblay (mtremblay@ cheo.on.ca) is corresponding author. 
remained elusive. ${ }^{10}$ For example, trends over the past 12 years from the Canadian Report Card on Physical Activity for Children and Youth show a general improvement in structures and supports for physical activity, yet no commensurate improvement in physical activity behaviors. ${ }^{11}$ The general lack of progress may be related to insufficient effort or investment; lack of or poorly implemented policies, programs, and practices; an inadequate period of sustained effort; and/or there may be a mismatch between strategies and requirements for systemic behavioral change.

The development and release of Report Cards on physical activity for children and youth have been used in many countries for advocacy and social mobilization to increase young people's activity by influencing perceptions, priorities, policies, and practices. ${ }^{12-14}$ In 2014, 15 countries produced and released Report Cards following a harmonized process, resulting in a Global Matrix of Grades. ${ }^{15}$ This cross-country comparison model produced provocative findings showing that lower levels of structure, strategies, and investments to promote physical activity for children and youth were actually related to higher levels of overall physical activity, which challenges the conventional thinking "if you build it they will come." 15 This paradoxical finding suggests a "one size fits all" approach, or one informed only by evidence from high-income countries (HIC), may need to be challenged or reconsidered.

The relationship between household income and child physical activity shows considerable between-country variation with a positive correlation observed in HIC and a negative correlation generally observed in lower-income countries (LIC). ${ }^{7,15}$ Similar interactions have been observed with childhood obesity levels ${ }^{16}$ and physical activity levels in adults. ${ }^{17}$ These findings are consistent with observations of the epidemiological, nutrition, and physical activity transitions. ${ }^{18-20}$ Furthermore, country-level factors, such as per capita income, income inequality, and Human Development Index (HDI, http://hdr.undp.org/en/content/human-development-indexhdi) have been shown to be related to levels of childhood physical activity in different ways in different countries. ${ }^{7,21,22}$

With escalating interest in global solutions to current childhood inactivity and obesity levels, ${ }^{4,6,10}$ it is responsible and pragmatic to reflect on the universality of proposed solutions and shared experiences to such pandemics. Given the lack of progress resulting from purported solutions, ${ }^{10}$ a revisiting of such approaches, with evidence across multiple cultures, countries, and geographies, is warranted. The Global Matrix of Grades cited previously ${ }^{15}$ was a pilot effort in this regard; however, it was recognized that this initial effort was limited by the relatively small number of participating countries.

Building on the success of the Global Matrix 1.0 in 2014, ${ }^{15}$ the lead investigators from each country committed to repeating and further developing the Global Matrix initiative. ${ }^{16}$ Accordingly, the Global Matrix 2.0 project was initiated. ${ }^{23}$ The purposes of this article are to describe the Global Matrix 2.0 project, consolidate findings from participating countries, analyze global variations, discuss areas in which countries are leading and lagging and explore why, and provide lessons learned from the project in the form of recommendations for improving the grades in all countries.

\section{Methods}

In July of 2014 the Active Healthy Kids Global Alliance distributed an open call through established networks for interested countries to participate in the Global Matrix 2.0 project. Countries were required to register their interest by the deadline of October 2015 and pay a modest participation fee (US \$500) to cover costs associated with the project. Forty countries from 6 continents responded and 38 fully participated in the Global Matrix 2.0. Each participating country was assigned a mentor who had participated in the Global Matrix 1.0 to guide them, ensure adherence to the harmonized processes, ${ }^{12}$ and make sure they stayed on schedule.

Similar to the Global Matrix 1.0, ${ }^{15}$ all countries gathered the best and most recent available evidence, or in some cases collected data prospectively, and reported on 9 common indicators (Behaviors: Overall Physical Activity, Organized Sport Participation, Active Play, Active Transportation, Sedentary Behavior; Sources of influence: Family and Peers, School, Community and the Built Environment, and Government Strategies and Investments). Writing groups employed a rigorous and transparent process for information and data gathering, to synthesize findings and reach consensus, and followed a harmonized Report Card development process. Each country engaged a diverse set of national experts from multiple sectors related to physical activity and adhered to a standardized grading framework. Full details of the Report Card development process have been previously described. ${ }^{12,13,15}$ The Report Card was designed as a knowledge synthesis, translation, and mobilization instrument serving as an advocacy mechanism to drive social action by stimulating debate, motivating policy, practice, and action, and inspiring change. ${ }^{12,13,15}$ Consequently, some countries added other indicators to their Report Cards (eg, obesity, physical fitness, movement skills, nongovernment strategies and investments) beyond the 9 common indicators (also used in Global Matrix 1.0). In 2 cases, common indicators were not graded (Qatar, Active Transportation; Scotland, School). Details of the process, data availability, and involvement of experts in each country are described in this supplemental issue of the Journal of Physical Activity and Health. ${ }^{24-61}$ Central to the process in each country was the gathering of the best available evidence, interpretation by the expert committee formed, and transparent reporting.

The grading framework and benchmarks used are provided in Tables 1 and 2 . While the quality and quantity of data and evidence available in each country varied substantially, countries were advised to consider and synthesize the best available evidence for each indicator. This is the same process employed for the Global Matrix 1.0. The expert committee, comprised of different stakeholders, in each country discussed the total evidence base, added their expert opinion, and reached consensus on the grade assigned for each indicator. The rationale for each assigned grade is provided in the respective country articles. ${ }^{24-61}$ Despite variation in country data sources it is believed that the grades across all indicators provide a basis for comparison, and are informative of global variation in these indicators related to the physical activity of children and youth.

Each country packaged their findings in a short-form highlight Report Card and/or long-form Report Card that provided substantiation of the grades and full data source information, as well as a list of expert committee members. Countries developed a "cover story" based on important themes in their Report Card findings, to help promote the Report Card, its findings, and recommendations. Illustrations of the cover story from each country are provided in the country-specific articles. ${ }^{24-61}$ Complete copies of each country's Report Cards are available at www.activehealthykids.org. The Global Matrix 2.0 findings and each country's Report Card were presented at the International Congress on Physical Activity and Public Health in Bangkok, Thailand in November 2016.

In addition to descriptive presentation and narrative interpretation of results within and between countries, quantitative analyses were also performed. A correlational analysis was performed to determine the extent to which Report Card grades were related 
Table 1 Grading Framework for the Report Card

\begin{tabular}{ll}
\hline Grade & Interpretation \\
\hline$A$ & We are succeeding with a large majority of children and youth $(\geq 80 \%)$. \\
$B$ & We are succeeding with well over half of children and youth $(60-79 \%)$. \\
$C$ & We are succeeding with about half of children and youth $(40-59 \%)$. \\
$D$ & We are succeeding with less than half but some children and youth $(20-39 \%)$. \\
$F$ & We are succeeding with very few children and youth $(<20 \%)$. \\
$I N C$ & Incomplete-inadequate information to assign a grade. \\
\hline
\end{tabular}

Note. "+" and "“" signs are added to the grades in some circumstances to indicate the high or low end of the grade continuum respectively and/or to indicate the presence ("“") or absence ("+") of significant gender, geographic, ethnic, or socioeconomic disparities.

\section{Table 2 Benchmarks Used to Guide the Grade Assignment for Each Indicator}

\begin{tabular}{l}
\hline Indicator \\
\hline Overall Physical Activ \\
Organized Sport Particip \\
Active Play \\
Active Transportation \\
Sedentary Behavior \\
Family and Peers
\end{tabular}

School

Community and the Built Environment

Government Strategies and Investments

\section{Benchmark}

$\%$ of children and youth who meet physical activity guidelines

$\%$ of children and youth who participate in organized sport and/or physical activity programs

$\%$ of children and youth who engage in unstructured/unorganized active play for several hours a day

$\%$ of children and youth who use active transportation to get to and from places (school, park, mall, friend's place)

$\%$ of children and youth who meet sedentary behavior or screen-time guidelines

$\%$ of parents who facilitate physical activity and sport opportunities for their children (eg, volunteering, coaching, driving, paying for membership fees and equipment)

$\%$ of parents who meet the physical activity guidelines for adults

$\%$ of parents who are physically active with their kids

$\%$ of children and youth with friends and peers who encourage and support them to be physically active

$\%$ of children and youth who encourage and support their friends and peers to be physically active

$\%$ of schools with active school policies (eg, Daily Physical Activity, recess, "everyone plays" approach, bike racks at school, traffic calming on school property, outdoor time)

$\%$ of schools where the majority ( $\geq 80 \%$ ) of students are taught by a Physical Education specialist

$\%$ of schools where the majority ( $\geq 80 \%$ ) of students are offered at least 150 minutes of Physical Education per week

$\%$ of schools that offer physical activity opportunities (excluding Physical Education) to the majority ( $\geq 80 \%)$ of students

$\%$ of parents with children and youth who have access to physical activity opportunities at school in addition to Physical Education

$\%$ of schools with students who have regular access to facilities and equipment that support physical activity (eg, gymnasium, outdoor playgrounds, sporting fields, equipment in good condition)

$\%$ of children or parents who perceive their community/municipality is doing a good job at promoting physical activity (eg, variety, location, cost, quality)

$\%$ of communities/municipalities that report they have policies promoting physical activity

$\%$ of communities/municipalities that report infrastructure (eg, sidewalks, trails, paths, bike lanes) specifically geared toward promoting physical activity

$\%$ of children or parents with facilities, programs, parks and playgrounds available to them in their community

$\%$ of children or parents living in a safe neighborhood where they can be physically active

$\%$ of children or parents reporting well-maintained facilities, parks/playgrounds in their community that are safe

$\%$ of children and youth who report being outdoors for several hours a day

Evidence of leadership and commitment in providing physical activity opportunities for all children and youth Allocated funds and resources for the implementation of physical activity promotion strategies and initiatives for all children and youth

Demonstrated progress through the key stages of public policy making (ie, policy agenda, policy formation, policy implementation, policy evaluation and decisions about the future) 
to several global descriptors and demographic indices, including: the HDI (2014 data calculated from life expectancy at birth, mean and expected years of schooling, gross national income per capita; greater scores represent greater human development), ${ }^{62}$ the Gini Index (1995-2013 data calculated from distribution of income; greater scores represent greater income inequality), ${ }^{63}$ the Gender Inequality Index (2014 data calculated from maternal mortality ratio and adolescent birth rates, proportion of parliamentary seats occupied by females and proportion of adult females and males aged 25 years and older with at least some secondary education, labor force participation rate of female and male populations aged 15 years and older; greater scores represent greater gender inequality), ${ }^{64,65}$ the Global Food Security Index (2016 data calculated from measures of affordability, availability, quality, and safety; greater scores represent greater food security), ${ }^{66}$ summer Olympic medal count (indicator of sporting success; 1896-2016 data), ${ }^{67}$ and distance from the Equator (broad indicator of climate/weather/temperature/ seasonal variations; calculated from the geographic center of each country ${ }^{68}$ using a latitude/longitude distance calculator). ${ }^{69}$ England, Scotland, and Wales were grouped together for this analysis because these indices had data for Great Britain only and not the individual countries.

All Report Card letter grades were converted to numeric ordinal scores $(A=5, B=4, C=3, D=2, F=1)$. For simplicity, signed letter grades were treated as nonsigned letter grades (eg, $A+, A-, A$ $=5$ ) for the conversion. The arithmetic mean (overall Report Card grade) was calculated for each country by summing the ordinal scores for all 9 common indicators and dividing by the number of ordinal scores. The behavior grade and the sources of influence grade were calculated similar to the overall Report Card grade but with the ordinal scores limited to the Behaviors (Overall Physical Activity, Organized Sport Participation, Active Play, Active Transportation, Sedentary Behavior) and Sources of Influence combined with Government Strategies and Investments common indicators, respectively. Due to the ordinal nature of the grade data, Spearman's rank correlation coefficients were calculated. Statistical significance tests were also performed on these coefficients and $\alpha$ was adjusted for multiple comparisons $(0.05 / 18=0.003)$. All correlation and significance tests were performed using $\mathrm{R}$ version 3.3.0 (Vienna: The R Foundation for Statistical Computing Platform).

\section{Results}

Figure 1 depicts the global dispersion of the countries participating in the Global Matrix 2.0. The 38 participating countries represent approximately $20 \%$ of the countries in the world (including all inhabited continents), $40 \%$ of the world's land mass, $60 \%$ of the world's population, and $>150 \%$ increase in participating countries compared with the Global Matrix 1.0.23

The consolidated findings are summarized in the form of a Global Matrix, which demonstrates substantial variation in grades both within and across countries (Table 3). The Global Matrix 2.0 results are presented in different formats to facilitate interpretation. Table 3 presents the Global Matrix 2.0 with grades organized by country, listed alphabetically within continents. Table 4 presents the countries organized hierarchically by grade for each indicator. These tables show a large spread in grades across countries (Overall Physical Activity $F$ to $A$-; Organized Sport Participation $F$ to $A$; Active Play $F$ to $B$; Active Transportation $F$ to $A$; Sedentary Behaviors $F$ to

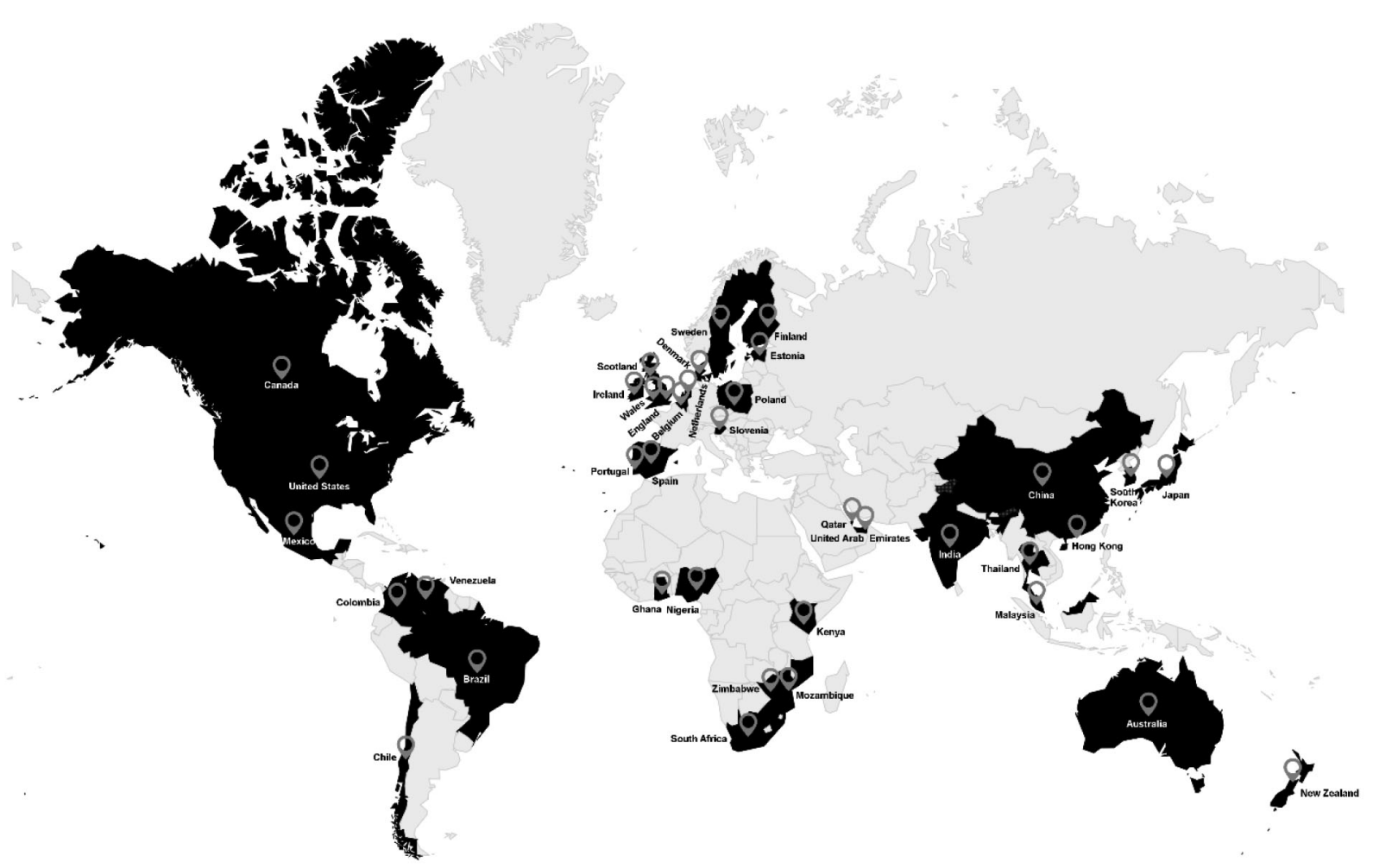

Figure 1 - Global map indicating the location of countries participating in the Global Matrix 2.0 (in black). 


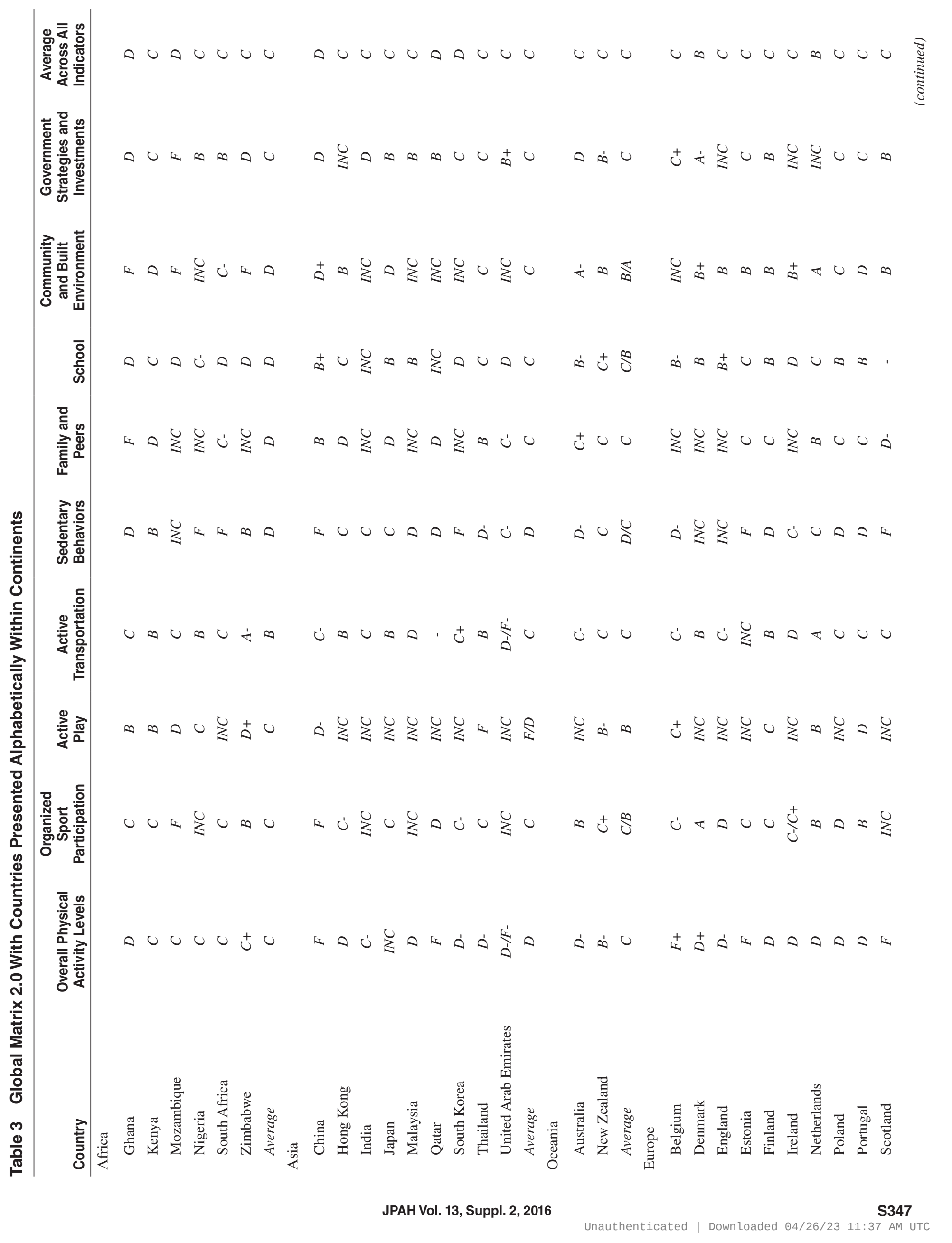




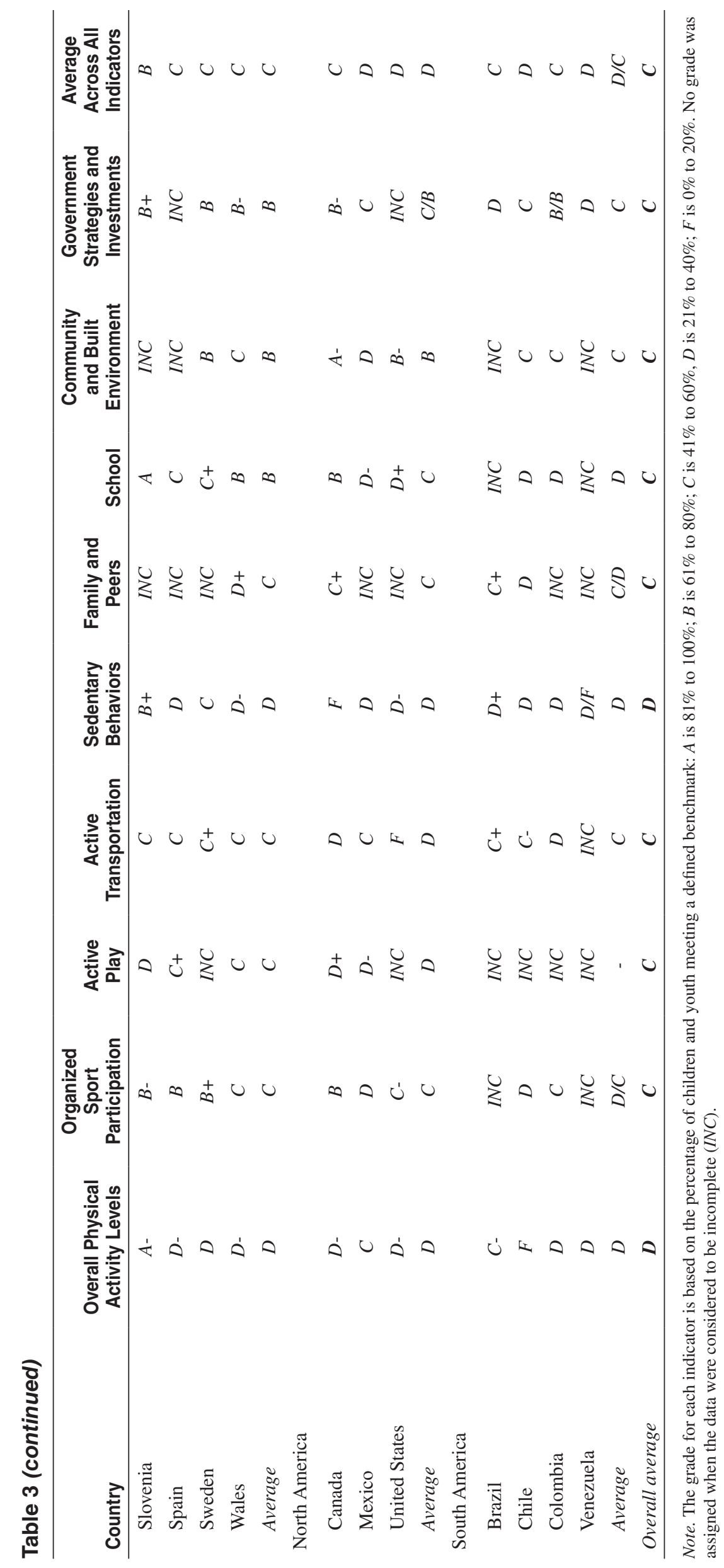




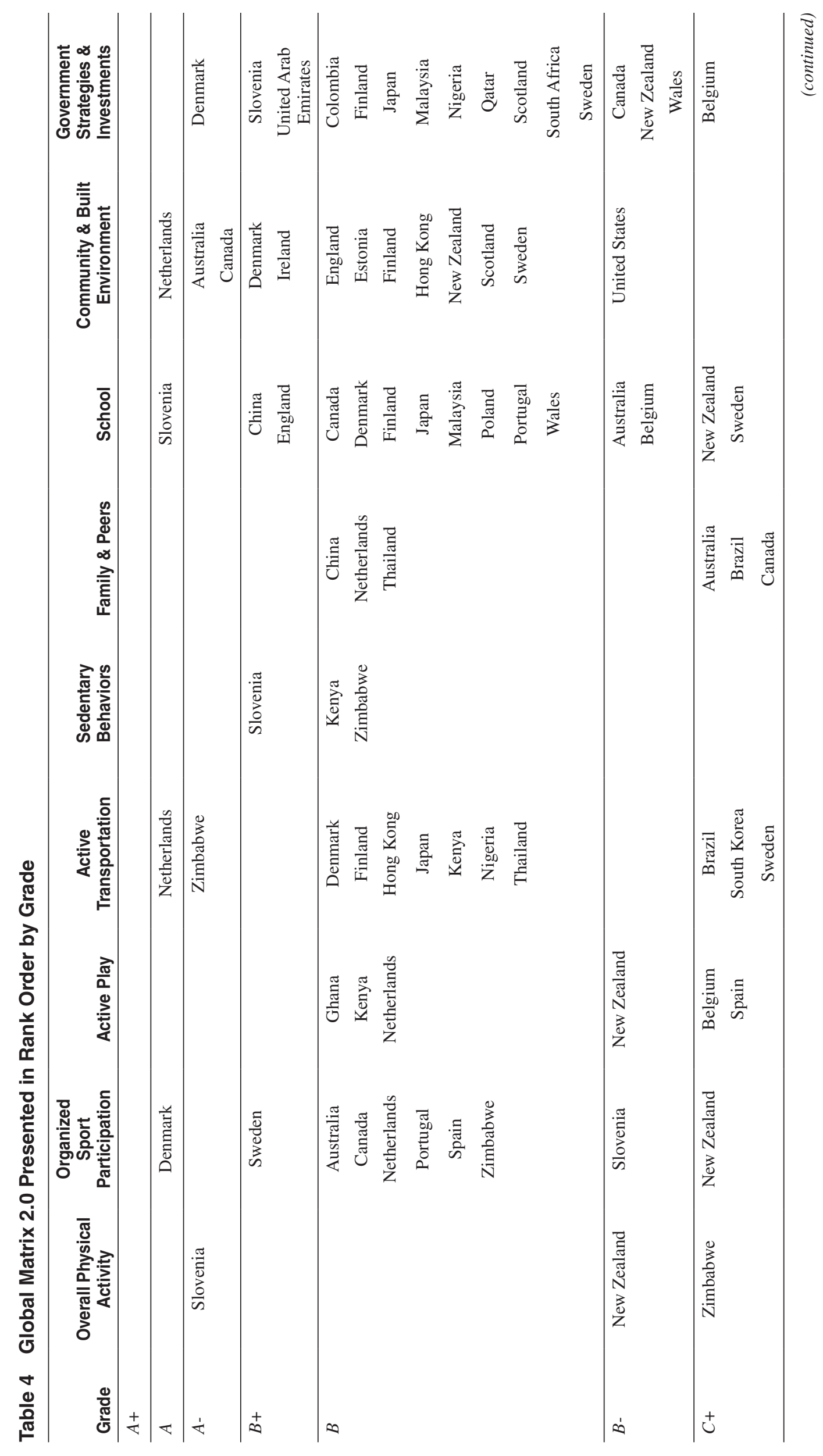




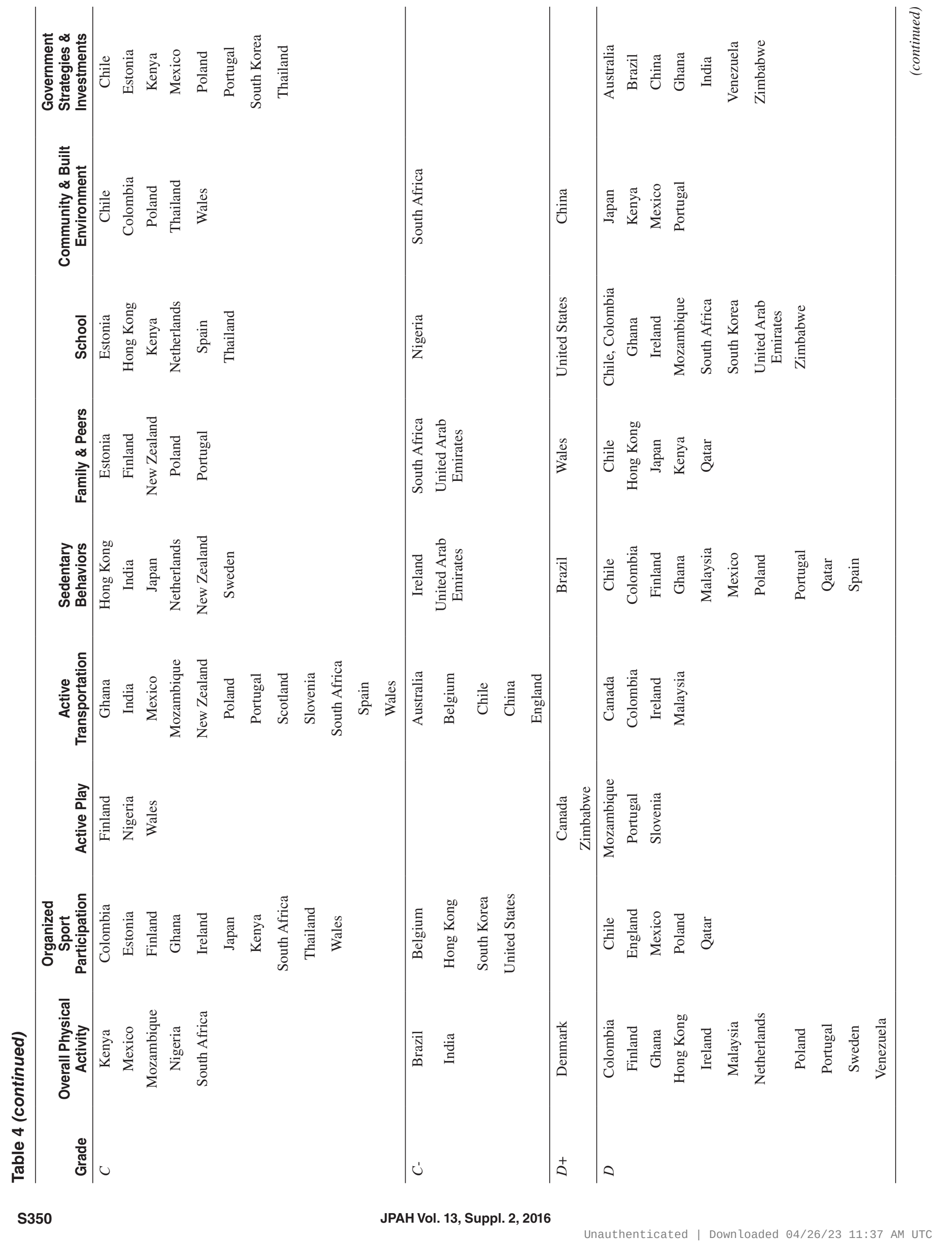




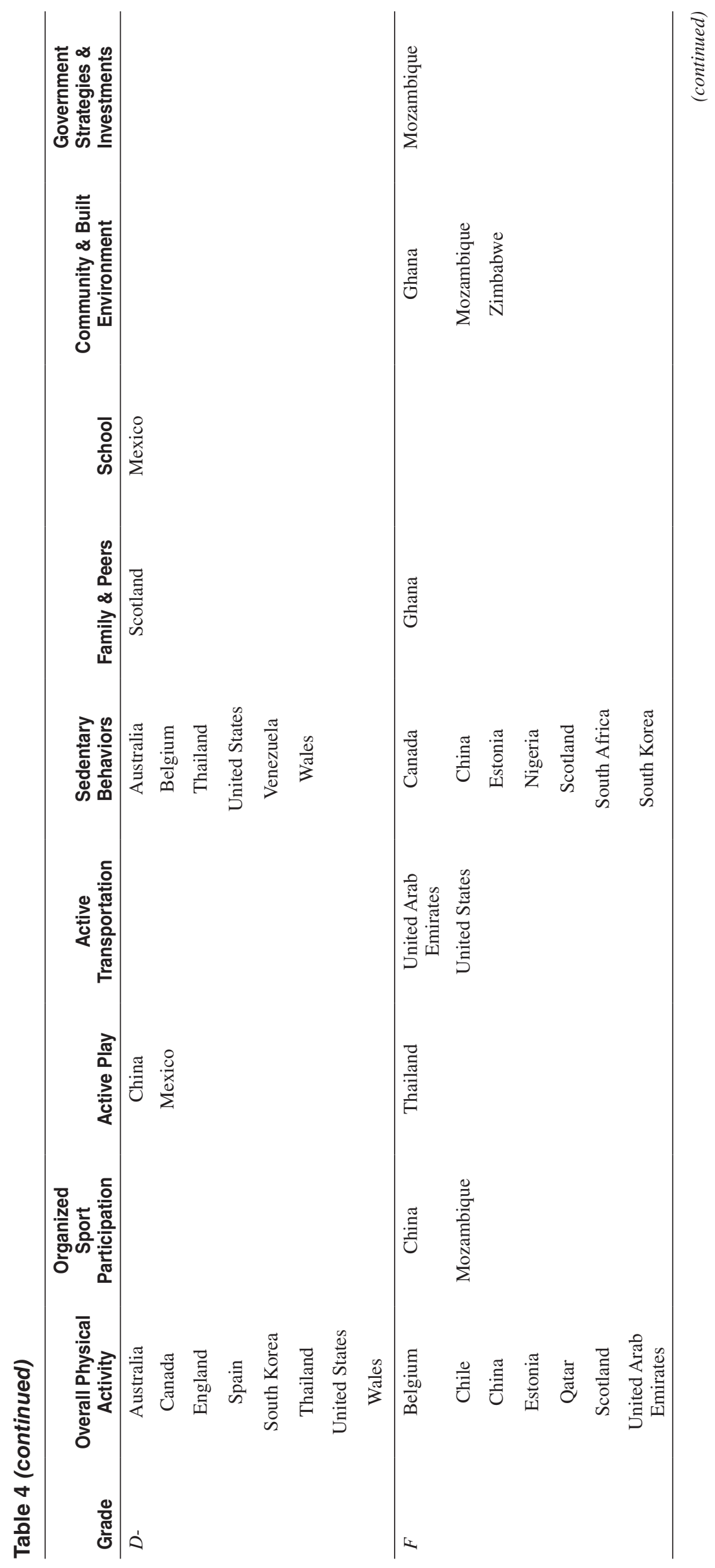

JPAH Vol. 13, Suppl. 2, 2016 


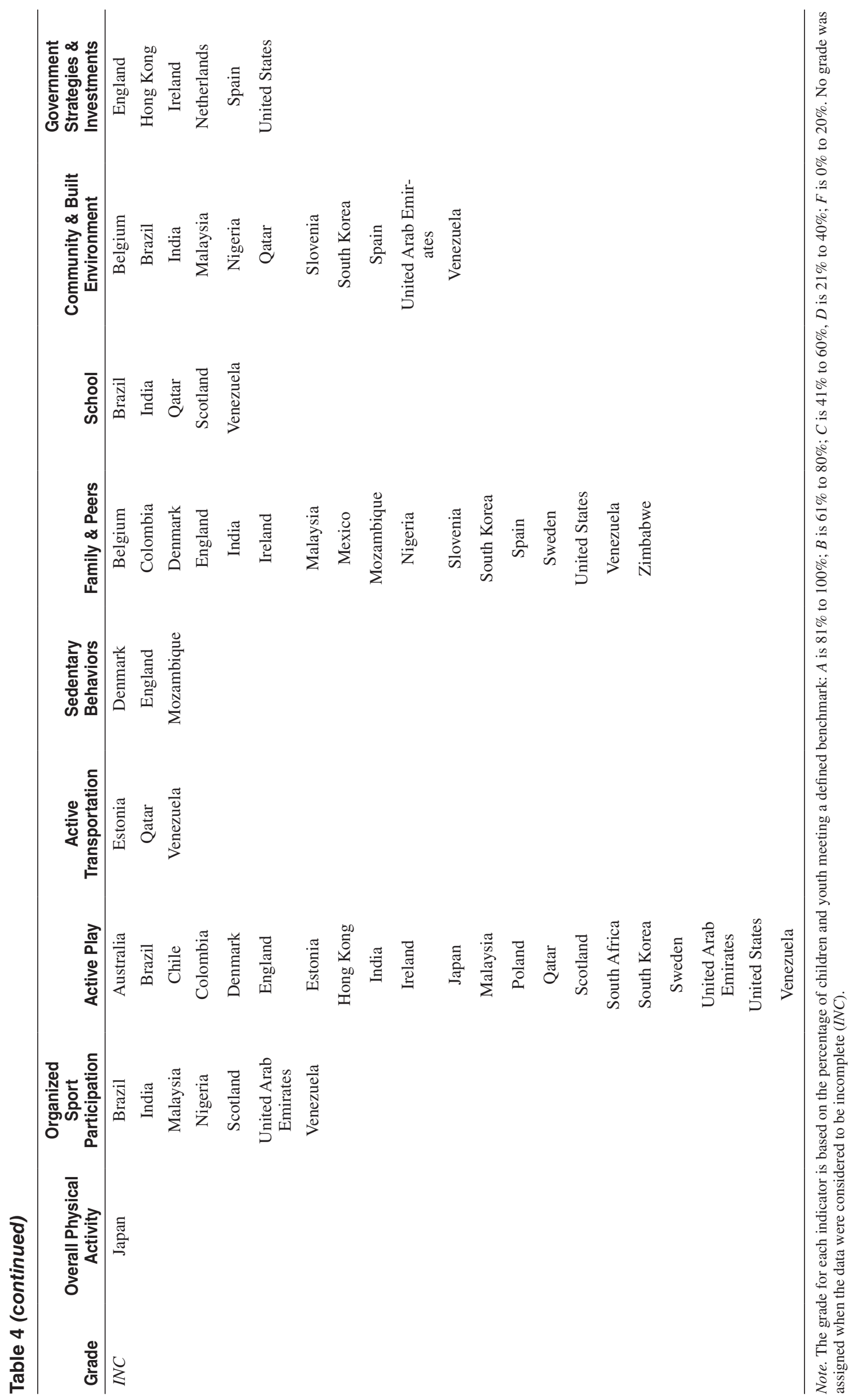


$B+$; Family and Peers $F$ to $B$; School $D$ - to $A$; Community and the Built Environment $F$ to $A$; Government Strategies and Investments $F$ to $A-)$ and that most countries are having both successes and challenges. Several countries had inadequate information to assign a grade (INC), most notably for Active Play (21 countries) and Family and Peers (17 countries). Venezuela was the most evidence-limited country, reporting $I N C$ grades for 6 of 9 indicators, ${ }^{59}$ although the definition of insufficient evidence to record a grade of INC varied across countries.

The findings showed that on average the grades were low $(D)$ for Overall Physical Activity, Active Play, and Sedentary Behavior (Table 3). The grades for sources of influence were generally higher than the behavior grades. The Community and the Built Environment indicator had the highest overall grade, though 12 countries reported INC. Overall behavior grades (Overall Physical Activity, Organized Sport Participation, Active Play, Active Transportation, Sedentary Behavior) were lower in participating Asian, North American, and South American countries compared with countries from the other continents. Average grades across all indicators were highest in Denmark, ${ }^{31}$ Slovenia, ${ }^{51}$ and the Netherlands. ${ }^{44}$ Sixteen countries reported at least $1 F$ grade and 30 countries reported at least $1 D$ grade. In contrast, only 6 countries reported at least $1 \mathrm{~A}$ grade.

Results of the correlational analysis of grades according to several global descriptors and demographic indices are presented in Table 5. No significant relationships were observed with Overall Behavior grades. For the Sources of Influence grades, strong positive relationships were observed with $\mathrm{HDI}^{62}$ and Global Food Security Index, ${ }^{66}$ while strong negative relationships were observed with the Gini Index ${ }^{63}$ and Gender Inequality Index ${ }^{64,65} \mathrm{~A}$ significant positive relationship with distance from the equator ${ }^{68,69}$ was also observed. No significant relationship between grades and summer Olympic medal count ${ }^{67}$ was observed, although it did show a rather strong positive correlation with Sources of Influence grades.

The Community and the Built Environment indicator received high grades in HIC and lower grades in LIC. There was a pattern of higher Overall Physical Activity in countries reporting poorer infrastructure (ie, grades on Sources of Influence), and lower Over- all Physical Activity in countries reporting better infrastructure. Similarly, some countries have relatively high grades for the policy environment but relatively low grades for the health behavior indicators the policies are targeting (for countries with $A$ or $B$ grades for Government Strategies and Investments Spearman's rho (Overall Physical Activity $\sim$ Government grade $)=-0.17, P=.58)$.

\section{Discussion}

The findings from this paper represent the richest and most diverse comparison of physical activity-related indicators for children and youth assembled to date, involving 38 countries from 6 continents. The wide range of grades observed, from $A$ to $F$ for most indicators, demonstrates that success is possible, at least for some countries. This reality provides for creative and innovative learning opportunities across countries and reinforces, while extending, the learning gained from the Global Matrix 1.0.15 Because of the substantial variation in grades, the global matrix provides a useful framework for consolidating and assessing the best available evidence aimed at understanding differences between and within countries. From Tables 3 and 4 it is clear that no one country is leading or lagging in all indicators but, rather, each country has a blend of successes and challenges. ${ }^{24-61}$ Not surprisingly, the wide distribution of grades results in global average grades for all indicators being $D$ or $C$. The evidence contained in the Global Matrix 2.0 shows that the challenge of enhancing physical activity behaviors and opportunities for children and youth around the world remains unresolved, and tackling this challenge together may provide unique insights, motivation, and synergy that could not be achieved in isolation.

The overall findings from the Global Matrix 2.0 showed that on average the grades were low for Overall Physical Activity, Active Play, and Sedentary Behavior, reinforcing the global concern about childhood physical activity levels. ${ }^{15,70}$ Similar to the Global Matrix 1.0, the grades for sources of influence were generally higher than the behaviors they aim to influence, suggesting that "making the healthy choice the easy choice" through environmental and policy supports has a substantial latent period before the influence

Table 5 Correlation Matrix (Spearman's rho) of Average Country Report Card Grades by Global Descriptors

\begin{tabular}{|c|c|c|c|c|c|c|}
\hline & \multicolumn{2}{|c|}{ Health and Education } & \multirow[b]{2}{*}{$\begin{array}{c}\text { Income } \\
\text { Distribution }\end{array}$} & \multirow[b]{2}{*}{ Nutrition } & \multirow{2}{*}{\multicolumn{2}{|c|}{ Other }} \\
\hline & Income & $\begin{array}{l}\text { Empowerment } \\
\text { and Labor }\end{array}$ & & & & \\
\hline & $\begin{array}{l}\text { Human } \\
\text { Development } \\
\text { Index }^{62}\end{array}$ & $\begin{array}{l}\text { Gender } \\
\text { Inequality } \\
\text { Index }\end{array}$ & Gini Index 63 & $\begin{array}{c}\text { Global Food } \\
\text { Security Index }\end{array}$ & $\begin{array}{l}\text { Summer Olympic } \\
\text { Medal Count }{ }^{67}\end{array}$ & $\begin{array}{c}\text { Distance from } \\
\text { the Equator } \\
(\mathrm{km})^{68}\end{array}$ \\
\hline $\begin{array}{l}\text { Rank (Highest, } \\
\text { Lowest) }\end{array}$ & $\begin{array}{c}0.935 \text { (Australia) } \\
0.416 \text { (Mozam- } \\
\text { bique) }\end{array}$ & $\begin{array}{c}0.016 \text { (Slovenia) } \\
0.591 \text { (Mozam- } \\
\text { bique) }\end{array}$ & $\begin{array}{c}25.6 \text { (Slovenia), } \\
63.4 \text { (South } \\
\text { Africa) }\end{array}$ & $\begin{array}{l}86.6 \text { (United } \\
\text { States), } \\
29.4 \text { (Mozam- } \\
\text { bique) }\end{array}$ & $\begin{array}{c}\text { 2,520 (United } \\
\text { States), } \\
2 \text { (Mozambique) }\end{array}$ & $\begin{array}{c}2 \text { (Kenya), } \\
7,219 \text { (Finland) }\end{array}$ \\
\hline $\begin{array}{l}\text { Overall Report Card } \\
\text { Grade }^{\mathrm{a}}\end{array}$ & 0.32 & $-0.55^{*}$ & -0.44 & 0.30 & 0.17 & 0.29 \\
\hline Behavior Grade ${ }^{b}$ & 0.12 & -0.26 & -0.23 & 0.19 & 0.04 & 0.07 \\
\hline $\begin{array}{l}\text { Sources of Influence } \\
\text { Grade }^{c}\end{array}$ & $0.60 *$ & $-0.77 *$ & $-0.55^{*}$ & $0.58 *$ & 0.45 & $0.48 *$ \\
\hline
\end{tabular}

$* P<.003$ (note: due to multiple comparisons, $\alpha=.003[0.05 / 18]$ ).

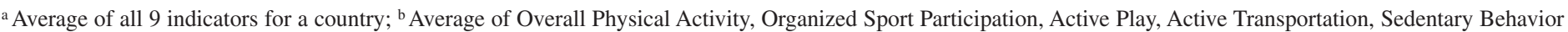
indicator grades; ${ }^{\mathrm{c}}$ Average of Family and Peers, School, Community and the Built Environment, and Government Strategies and Investments indicator grades. 
is translated into behavior change, or it is not as strong a behavior driver as generally believed.

While there are successes and challenges across countries, the grades for Denmark, ${ }^{31}$ the Netherlands, ${ }^{44}$ and Slovenia ${ }^{51}$ generally showed greater success. In these countries there is both a welldeveloped infrastructure and policy support network for healthy active living as well as individual commitment to habitual physical activity embedded in all aspects of life (eg, recreation, play, transportation, school).

The Danish Report Card illustrates that despite a high priority at a governmental level to facilitate physical activity and many strategies to promote physical activity, a large proportion of Danish children seem not to comply with the recommendation for physical activity. This highlights that even if a country performs very well at the strategic and political level, the impact at the individual level is not assured. There is a gap between the governmental level and the individual level that needs to be bridged to increase physical activity and decrease sedentary behavior in children. So despite the relatively high average grade across all indicators, the grade that is most coveted, Overall Physical Activity, remains below desired levels.

In the Netherlands, every city or village has an extensive layout of cycle paths and routes. In many urban areas separate cycle paths are not uncommon. Further, there is a high percentage of bike ownership: $84 \%$ of the Dutch inhabitants from age 4 years and older own a bicycle. ${ }^{44}$ Furthermore, many municipalities are promoting bike use and are banning cars from the inner cities. However, despite robust policies and infrastructure, these supports are not sufficient to score highly on Overall Physical Activity (based on the available measures). ${ }^{44}$

In Slovenia, physical activity in children is closely monitored within the school system. Every April, the majority of Slovenian children and youth (aged 6 to $19 \mathrm{y}$ ) are included in nation-wide, school-based physical fitness measurements. This initiative is called SLOfit - the Sport Educational Chart program. SLOfit is obligatory for all Slovenian primary and secondary schools across the country. For more than 30 years, this system has given teachers, researchers, and policy-makers access to high-quality, standardized data on physical fitness, which in turn allows for relatively responsive evidence-based policy adjustments when needed. For example, based on more recent evidence of declining physical fitness from the SLOfit database, Slovenia introduced a health-oriented physical activity intervention program called Healthy Lifestyle in the school year 2010/2011, offering children 2 optional, additional hours of physical activity per week. Healthy Lifestyle is considered part of a school's regular extracurricular health-oriented physical activity program. This project currently includes more than $30 \%$ of the entire primary-school population. Before this initiative, Slovenian children had been experiencing negative trends in motor and physical fitness for over 2 decades, but since 2011, physical fitness in 6- to 14-year-olds has been steadily improving. ${ }^{71}$

While Denmark, the Netherlands, and Slovenia are each generally overcoming challenges more successfully than other countries, the key to their success is not uniform, suggesting multiple strategies can, and perhaps should, be pursued in an effort to improve Report Card grades.

\section{Successes and Challenges Based on Indicator Grades}

Findings for each of the 9 common indicators are discussed further in subsections below.
Overall Physical Activity. Slovenia reported the highest grade $(A-)^{51}$ for Overall Physical Activity while 20 countries reported low $(D)$ and 7 countries failing $(F)$ grades, suggesting there is widespread evidence of a childhood physical inactivity crisis. One country (Japan) assigned an INC grade. ${ }^{39}$ The high grade achieved in Slovenia is attributed to highly developed and apparently effective structured physical activity opportunities through school physical education and structured sport opportunities both in school and in the community. ${ }^{51}$ The low grades in most countries are consistent with earlier reports. ${ }^{7,15,70}$ Grades were generally higher in low-middle income countries (LMIC; Brazil, ${ }^{26}$ India, ${ }^{37}$ Kenya, ${ }^{40}$ Mexico, ${ }^{42}$ Mozambique, ${ }^{43}$ Nigeria, ${ }^{46}$ South Africa, ${ }^{52}$ Zimbabwe ${ }^{61}$ ), but this relationship was not uniform as Slovenia ${ }^{51}$ and New Zealand ${ }^{45}$ also reported high grades and no significant correlation between HDI and overall behavior grades was observed (Table 5).

Caution needs to be employed when interpreting direct comparisons among countries because of significant variation in sampling and measurement procedures. Despite these well-described limitations, ${ }^{72,73}$ some insights can be drawn from the variations observed in global physical activity levels. The findings seen in the Global Matrix 2.0 were also seen with the International Children's Accelerometry Database, which showed that North American children were less active than those in Northern Europe. ${ }^{74}$ The lower overall behavior grades reported by Asian, North American, and South American countries compared with countries from the other continents is consistent with a recent report of variations in the cardiorespiratory fitness levels of children and youth across 50 countries. ${ }^{75}$ The best performing countries on the 20 -m shuttle run were from Africa and Northern Europe while countries from South America were consistently among the worst performing countries. ${ }^{75}$ The Report Card overall grades showed negative relationships with Gini Index (country-specific income inequality) ${ }^{63}$ and Gender Inequality Index, ${ }^{64,65}$ indicating that greater inequality is associated with lower grades. A similar pattern was observed with the $20-\mathrm{m}$ shuttle run performances reported by Lang et al. ${ }^{75}$ The pattern of variability observed in the Overall Physical Activity grades is broadly consistent with the theory of an epidemiological ${ }^{18}$ and physical activity transition ${ }^{19}$ suggesting that countries with a higher HDI generally show lower physical activity behaviors commensurate with contemporary lifestyles influenced by automation and convenience. A systematic review of data from Sub-Saharan African school-aged children by Muthuri et $\mathrm{al}^{76}$ found inverse associations between physical activity and fitness, and urban living and higher socioeconomic status, suggesting that economic development may be related to reduced healthy active lifestyles and fitness. Nevertheless, the success achieved in Slovenia suggests that behavioral changes associated with such transitions are not inevitable.

Organized Sport Participation. The average grade for Organized Sport Participation was a $C$, the highest average grade for any of the behavior indicators. Denmark had the highest grade $(A)^{31}$ and 9 countries had grades of $B$ or higher. Only 7 countries reported grades of $D$ or $F$, and 7 countries reported $I N C$ grades. Nine out of the top 10 grades for this indicator were from HIC while the only $2 F$ grades were from LMIC. The average grade of $C$ indicates that approximately half of children and youth report participating in sport.

Grades for Organized Sport Participation seem positively related to grades on the School and Community and the Built Environment indicators [eg, countries with good grades for Organized Sport Participation also reported relatively good grades for School and Community and the Built Environment (eg, Australia, ${ }^{24}$ 
Canada, ${ }^{27}$ Denmark, ${ }^{31}$ the Netherlands, ${ }^{44}$ Sweden $^{55}$ ), whereas countries with low grades for Organized Sport Participation often reported low grades for School and Community and the Built Environment (eg, Chile, ${ }^{28}$ Mexico, ${ }^{42}$ Mozambique $\left.{ }^{43}\right)$ ]. This relationship was significant (Spearman's rho for Organized Sport Participation grade $\sim$ School + Community and Environment grades $=0.42$, $P=.02$ ) and is not surprising considering that organized sport opportunities require space, facilities, equipment, programs, safety precautions, and supervision. While most countries assigned grades for Organized Sport Participation, details of the quality, frequency, duration, intensity, context (eg, physical education, extracurricular, community sport), and seasonality of participation varied significantly and/or were generally lacking.

Active Play. No countries reported a grade of $A$ for Active Play; the highest grade was $B$ (Ghana, ${ }^{35}$ Kenya $^{40}$ the Netherlands ${ }^{44}$ ). Eight countries reported low grades ( $D$ or $F$ ). Notably, 21 countries reported INC grades, identifying the need for greater clarity on the definition and benchmarks, and subsequent surveillance of this important indicator. One problem often cited was the lack of valid and reliable measurement methodologies and instruments to accurately quantify Active Play; consensus is required on a definition for Active Play and how to measure it. No clear pattern of country characteristics associated with high or low grades emerged.

The 2015 ParticipACTION Report Card from Canada focused on active outdoor play ${ }^{77}$ and included a Position Statement on Active Outdoor Play developed by several organizations in Canada and informed by 2 systematic reviews. ${ }^{78-80}$ The benefits of active outdoor play (defined as freely chosen, spontaneous, and selfdirected physical activity involving an element of fun done in the outdoors) are diverse, substantial, and substantiated. ${ }^{78}$ Indeed, the trend-especially in HIC - is toward greater indoor time, which the Position Statement argues is in fact a greater risk than the outdoors, because of the greater likelihood of low physical activity, high sedentary behavior, relatively higher risk of contact with cyber-predators, greater incidental eating, and exposure to toxins in indoor air, among other factors. ${ }^{78} \mathrm{~A}$ recent report demonstrated that each additional hour spent outdoors is associated with 7 additional minutes of moderate- to vigorous-intensity physical activity (MVPA) and 13 less minutes of sedentary time, as well as lower odds of negative psychosocial outcomes, among 7- to 14-year-old Canadian children. ${ }^{81}$ Similarly, a study on 11-year-old children using objective monitoring in the United Kingdom reported that time spent outdoors resulted in nearly 3 times more physical activity than time spent indoors. ${ }^{82}$ Active play, especially in the outdoors, seems to be increasingly replaced by use of electronic screens for entertainment, used almost always indoors. ${ }^{77,78}$ This trend makes the careful monitoring and surveillance of active play important for guiding future strategies and interventions.

Much active play is likely light-intensity physical activity and may not be captured in the evaluation of the Overall Physical Activity grade. The importance of light-intensity physical activity, especially in the form of active play, is largely unknown and likely varies significantly among countries, between sexes, across ages, and in urban and rural areas. An emerging interest in the contribution of light-intensity physical activity, such as is typically obtained through Active Play, is evident in the recommendations from the World Health Organization Commission on Ending Childhood Obesity $^{83}$ and the new Canadian 24-Hour Movement Guidelines for Children and Youth. ${ }^{84}$ With play identified as a fundamental right of children, ${ }^{85,86}$ and with high levels of sitting ${ }^{87,88}$ and indoor time,${ }^{81}$ the opportunities to promote physical activity through an increase in active play, especially outdoors, are plentiful and should be a high priority. ${ }^{15,78}$

Active Transportation. Active Transportation grades showed a wide distribution with the Netherlands reporting an $A,{ }^{44}$ Zimbabwe an $A-{ }^{61} 7$ countries a $B, 19$ countries a $C, 5$ countries a $D, 2$ countries (United Arab Emirates, ${ }^{56}$ United States ${ }^{57}$ ) an $F$, and 3 countries an $I N C$. While active transportation may be a necessity for some children in countries such as Zimbabwe, ${ }^{61}$ Nigeria, ${ }^{46}$ and Kenya, ${ }^{40}$ in other countries with high grades it represents a choice that may be driven more by supportive policies and/or traditional cultural norms (eg, Denmark, ${ }^{31}$ Finland, ${ }^{34}$ the Netherlands ${ }^{44}$ ). Multicountry studies have shown similar proportions of active transportation involvement in significantly differing contexts. ${ }^{89,90}$ To understand these patterns a "need-based framework" has been proposed for LMIC, where active transportation represents the only option for transportation because motorized vehicle availability remains relatively low in comparison with HIC. The patterns observed in HIC can be understood within a "choice-based framework" where policies and infrastructure facilitate active transportation as an option to commute.

Interestingly, countries with high grades for this indicator come from very diverse climates, suggesting weather is not necessarily a key determinant. The grades for countries in Africa were on average better than grades from countries in other continents. The grades for North American countries were generally lower than those from other continents.

While active transportation has been associated with increased physical activity, ${ }^{91}$ cardiorespiratory fitness, ${ }^{91}$ and lower measures of adiposity, ${ }^{90}$ evidence suggests that levels of active transportation are declining. ${ }^{92-100}$ Generational declines in active transportation ${ }^{101,102}$ and independent mobility ${ }^{103}$ have also been observed. These trends are consistent with the increased fear of the outdoors and a convenience lifestyle. ${ }^{78}$ The fact that several countries have been able to resist or counter these trends is encouraging and provides for the transference of evidence and experiences between countries leading and lagging in this indicator. Active transportation, whether for school, work, chores, or play varies dramatically between urban and rural settings, especially in LMIC where motorized transport is often not available. ${ }^{19,101,104}$ It will be important to carefully monitor active transportation behaviors in rural areas in developing countries as motorized transport becomes increasingly available and subsistence demands become increasingly mechanized. ${ }^{19}$ During this transition in these needs-based circumstances, it is also important to monitor and mitigate the unintended consequence of pedestrian injuries associated with children actively commuting.

Sedentary Behavior. There is considerable global variation in grades for sedentary behaviors, although the majority of countries have very poor or failing grades. Slovenia, ${ }^{51}$ Kenya, ${ }^{40}$ and Zimbabwe ${ }^{61}$ had grades in the $B$ range while 24 countries had grades of $D$ or $F$. All continents had an average of a $D$ grade. These grades identify a serious and widespread problem of excess screen viewing ( $>2$ hours per day of recreational screen time $\left.{ }^{105,106}\right)$. Access to convenience and digital technology (eg, motorized vehicles, electronic screens) is likely facilitating sedentary behavior. Recent research comparing $17 \mathrm{HIC}$, middle-income countries (MIC), and LIC demonstrated that household ownership of televisions, computers, and cars increased as country income level increased; that ownership was positively associated with obesity and diabetes in LMIC; and this relationship was partially mediated by decreased physical activity and increased sedentary behavior. ${ }^{107}$ Temptations for sedentary behaviors are increasing as the world becomes increasingly cyber-centric, 
auto-dependent, and urbanized, consistent with epidemiological and physical activity transitions. ${ }^{18,19,101}$ Self-report sedentary behavior data on representative samples of children and youth from 42 countries revealed that $62 \%$ and $63 \%$ of 13 - and 15 -year-olds, respectively, watched $\geq 2$ hours of television per day on weekdays. ${ }^{7}$ Despite evidence that television viewing time in some countries may be decreasing among children, other sedentary screen time use (eg, computers, tablets, smartphones, electronic games) has more than compensated for this decline. ${ }^{7}$ Many parents agree that their children spend too much time watching television or playing electronic games. ${ }^{108}$

The overall findings from the Global Matrix 2.0 and international surveys suggest that when sedentary behaviors are high (ie, low grades), physical activity levels are low (Spearman's rho = $0.44, P<.01$ ). The study of sedentary behavior, from a movement behavior perspective, has gained significant momentum in recent years, in recognition of the significant relationship with measures of health and health risk. ${ }^{88,105-114}$ The ubiquity of low grades in the Global Matrix 2.0 suggests that public health messaging around limiting sedentary behavior, and screen time in particular, may be an important area of focus and research as lifestyle transitions occur throughout the world. Measures of screen time and related technologies are evolving rapidly and future surveillance must attempt to keep pace with this evolution. It should be noted that the sedentary behavior indicator in the Report Cards was informed in all countries exclusively by screen-time, or specifically television viewing time. In the future, measurement of nonscreen sedentary behaviors (eg, time spent sitting while not in front of screens), fragmentation of sedentary time (eg, interruptions, breaks), and research on their relationship with health outcomes are needed. At the present time, overall sedentary behavior (ie, total or leisure-time sitting) guidelines do not exist for children and youth, making it difficult to create benchmarks to inform the development of a grading rubric. Future research should be directed toward identifying dose-response relationships between total time spent in sedentary behaviors and health outcomes in children and youth, that will in turn inform the development of comprehensive sedentary behavior guidelines. In this regard, a recent meta-analysis by Liu et $\mathrm{al}^{3}$ suggests that screen time in children and adolescents is associated with depression risk in a nonlinear dose-response manner.

Family and Peers. China, ${ }^{29}$ the Netherlands ${ }^{44}$ and Thailand ${ }^{56}$ had the highest grades $(B)$ for the Family and Peers indicator, while Ghana ${ }^{35}$ had the lowest grade $(F)$. Similar to the Active Play indicator, many countries (17) assigned an INC grade. Participating experts and recent reviews ${ }^{115-118}$ support the importance of Family and Peers as a core indicator of the physical activity of children and youth; however, the lack of valid and reliable measurement instruments has led to a dearth of empirical data for the established benchmarks (Table 2). Countries from Africa had a lower average grade for the Family and Peers indicator compared with the other continents, perhaps suggesting that physical activity was more a routine requirement of daily living (eg, chores, active transportation, active play) with less attentiveness or need for family and peer support. Alternatively, a lower awareness of the importance of habitual physical activity may have contributed to this slightly lower continental average. Published literature in this area is difficult to find. A survey of parents in 25 countries with children up to 12 years of age in 2010 reported playing with their children an average of 14.3 hours per week in a typical week. ${ }^{108}$ Wide country variations were noted with means ranging from 10.5 hours in Denmark to 20.0 hours in China. ${ }^{108} \mathrm{~A}$ number of confounding variables, including family size and composition, employment logistics, urban-rural residence, climate, and variable definitions of "play" complicate the interpretation of these findings.

The importance of positive role modeling of parents and their support of childhood physical activity is well known. ${ }^{119-121} \mathrm{~A}$ recent cohort study reinforced the importance of parental role modeling for both physical activity and sedentary behavior, demonstrating significant associations between preschool children's behaviors and their parents, and further observing the potentially important role of same and different sex parental-child relationships. ${ }^{122}$ While the role of peers and parents in creating supportive environments for physical activity is unequivocal, drawing any firm insights from the Global Matrix 2.0 in this regard is difficult.

School. Grades for the School indicator ranged from $A$ in Slovenia ${ }^{51}$ to $D$ - in Mexico $^{42}$ with a relatively even distribution of grades by other countries between these extremes (Table 4). There was a clear trend toward higher grades in HICs and lower grades in LMICs. The high grade for Slovenia was associated with the fact that physical education is a standardized, compulsory subject in all primary and secondary schools. Although total activity hours can vary by grade level, from grade 6 through secondary school, $100 \%$ of physical education classes (and more than two-thirds in primary schools) are taught by physical education specialists with a university degree in that field. Regarding school sports infrastructure, all primary schools (and most secondary schools) have at least 1 sport hall fully equipped with the necessary sports equipment and additional outdoor facilities. All schools in Slovenia also have defined, explicit physical activity policies (eg, bike racks at school, traffic calming on school property, outdoor time). In general, the grades for School do not appear to be closely related to the Overall Physical Activity grades. This observation is supported by the average School grades by continent (Table 3) with Oceania, Europe, and North America reporting 2 full grades higher for the School indicator than the Overall Physical Activity indicators, whereas in Africa the School indicator was a full grade lower than the Overall Physical Activity Indicator.

International comparisons of school-based physical activity supports, opportunities, facilities, and policies are scarce. A recent comprehensive report of 30 European countries around school-based initiatives and strategies to promote and support physical education and school-based physical activity highlighted important differences across Europe ${ }^{123}$ and noted that in some countries time devoted to physical education was $<10 \%$ of total curricular time. ${ }^{123}$ To reduce costs and/or create more time for other subjects, a trend toward a reduction in the quality and/or quantity of physical education has been observed in many countries in recent years. ${ }^{124-126}$ In contrast, areas of Australia have shown small increases in time and resources committed to physical education. ${ }^{95,127}$ This apparent depreciation of physical education is unfortunate as recent research has shown that more MVPA is achieved on school days with a physical education class ( 9 more minutes in the United States and 16 more minutes in Finland) compared with those without. ${ }^{128}$ These differences account for a significant proportion of time toward meeting physical activity guidelines..$^{84,129}$ The relative importance of school-based support for physical activity may be greater in HICs where organized and structured physical activity is disproportionately relied upon.

Community and the Built Environment. For this indicator 3 countries (Netherlands, ${ }^{44}$ Australia, ${ }^{24} \mathrm{Canada}^{27}$ ) had grades in the $A$ range while Ghana, ${ }^{35}$ Mozambique, ${ }^{43}$ and Zimbabwe ${ }^{61}$ reported $F$ grades. Eleven countries reported an $I N C$ grade. All countries with 
a grade of $C+$ or higher were HICs whereas 7 out of 9 countries with a grade of $C$ - or lower were LMICs. Grades from participating countries in North America and Europe were higher than those from other continents. The general pattern of higher grades in HICs and lower grades in LMICs was consistent with the Global Matrix 1.0 and makes intuitive sense. The importance of improving the built environment to facilitate healthy active living and making the healthy choice the easy choice has gained significant popularity, especially in HICs. ${ }^{130}$ However, several countries report that the infrastructure for this indicator is already quite good. Countries with high grades for this indicator reported rather good physical activity infrastructure, availability, and programming, 24,27,31,38,44 but often without the desired impact on habitual physical activity. In fact, the Spearman's rho for the Overall Physical Activity grade $\sim$ Community and Built Environment grade is $-0.28(P=.18)$ and indicates an overall negative relationship, albeit weak.

Characteristics of the built environment are a potential source of influence on the physical activity level of children, youth, and adults. In a study using latent class analysis of built environment features reported by adults from 11 countries, 2 specific neighborhood patterns were positively associated with meeting physical activity guidelines: an overall activity supportive environment (eg, many shops and transit stops within walking distance, sidewalks on most streets, low-cost recreation facilities near-by) and highly walkable yet unsafe environments with few recreation amenities. ${ }^{131}$ The IPEN study also examined the associations between objectively measured characteristics of the environment and objectively measured physical activity in 14 countries, finding that residential density, intersection density, public transport density, and the number of parks in a $0.5 \mathrm{~km}$ buffer were linearly and positively associated to MVPA. ${ }^{132}$ Similar results were obtained in a descriptive review examining the association between children's physical activity and environmental attributes among 33 quantitative studies. ${ }^{133}$ Children's participation in physical activity was found to be positively associated with publicly provided recreational infrastructure (eg, access to recreational facilities and schools) and specific transport infrastructure (eg, presence of sidewalks and controlled intersections, access to destinations and public transportation) and negatively associated with more roads to cross, increased traffic density and speed, and unsafe local conditions. ${ }^{133}$

While it is intuitive and perhaps obvious that physical activity-promoting environments will encourage and ultimately lead to an increase in childhood physical activity, we need to be open to the possibility that either the perception of what constitutes a physical activity promoting environment may be incorrect, or that the built environment, organizational structure, or facilities alone may be insufficient to have a demonstrable impact on childhood physical activity levels. The physical, organizational, and social structurecentric approach commonly employed and seemingly preferred in HIC is arguably not working. As stated in the Global Matrix 1.0 article, ${ }^{15}$ 'in some cases it may be that 'less is more' for the promotion of exploratory play and incidental physical activity for some children," as seen more so in LMICs. This "less is more" approach is also supported by the Position Statement on Active Outdoor Play referred to earlier, ${ }^{78-80}$ which is less cost-intensive, is fundamentally more accessible for vulnerable, marginalized, rural, and remote populations, and is rooted in history. An increase in independence, including greater independent mobility and freedom to play, may turn out to be more effective at increasing habitual physical activity than more structured approaches. Playing outdoors in nature (eg, unstructured fields, bushes) might be more attractive to children than structured, hyper-safe yet unchallenging playgrounds. Based on the findings from the Global Matrix 2.0, such an approach at least deserves consideration and will require more social engineering than built environment engineering.

Government Strategies and Investments. Denmark ${ }^{31}$ reported the highest $(A-)$ grade for the Government Strategies and Investments indicator followed by Slovenia ${ }^{51}$ and the United Arab Emirates $^{57}(B+)$. Twelve other countries reported grades in the $B$ range while only 1 country (Mozambique ${ }^{43}$ ) reported an $F$ grade. In contrast to the Global Matrix 1.0 where 5 out of 15 countries assigned an INC grade, only 6 out of 38 countries in the Global Matrix 2.0 assigned INC grades. The continental average grades were rather uniform around the world, regardless of country HDI. The individual country Report Cards ${ }^{24-61}$ serve as a repository of government policies, strategies, and investments; however, a paucity of robust evaluations reduces the strength of the guidance that can be gleaned from these listings.

While most countries reported adequate to good government physical activity strategies and policies, several also noted a serious lack of implementation and dearth of quality assurance or evaluation. This policy-implementation disconnect may help to partially explain the paradox observed with greater infrastructure and support sometimes negatively associated with actual physical activity behavior. Implementation deficiencies can coexist with insufficient sustainability and scalability. Also plausible is the possibility that the social-cultural environment (eg, parental restrictions/societal norms on active and outdoor play) is counteracting what might otherwise be favorable policies and strategies for physical activity. Finally, policies and strategies may be reactive, rather than preventive, to problems after they had emerged, thus making evidence of effectiveness more difficult to demonstrate. Regardless, it remains prudent advice "to rally support for the implementation of proactive campaigns, strategies, and investments in developing countries in an effort to preserve inherent healthy active living behaviours." 15

Other Indicators. Many countries included additional indicators of country, cultural, professional, or political importance. These results are not presented or discussed in this paper, but examples of additional indicators included body weight status, nutrition/ healthy eating indicators, physical fitness, movement skills, and nongovernmental strategies and investments, among others. Details are reported in individual country Report Cards. ${ }^{24-61}$

\section{Disparities and Inequities}

Disparities and inequities are evident and variable in the Global Matrix 2.0 in several ways. The most obvious may be at the country level with some countries reporting better grades than others. It is this variation that makes the process informative and can lead to insights that may help to "level the playing field" across countries. Also obvious from an examination of the individual country Report Cards ${ }^{24-61}$ is the lack of data and consequent discussion related to children and youth with a disability (physical, mental, sensory), similar to the Global Matrix 1.0. ${ }^{15}$ This large and particularly vulnerable group arguably has the most to gain from a "level playing field." The prevalence of children and youth with disabilities varies substantially among countries and disability category ${ }^{134,135}$ and the Global Matrix process could help to identify and circulate best-practice strategies.

Similar to the Global Matrix 1.0, the most notable withincountry disparity or inequity was seen with the Organized Sport Participation indicator, likely because of the resource requirement for registration fees, equipment, and travel. This disparity is 
evident with socioeconomic (favoring middle- and high-income), geographic (favoring urban dwelling), and sex (favoring boys) gradients. The attention paid to such gradients in most Report Cards was rather superficial and represents an important area for improvement in future international comparison efforts. Indeed, the strong and significant negative correlation seen between both the Gini Index ${ }^{63}$ and Gender Inequality Index, ${ }^{64}$ and Sources of Influence for physical activity (Table 5) suggests that country level indices of inequality and empowerment may be important targets, or beacons, for innovative interventions.

Other international comparison research has shown interesting interactions between physical activity and outcome indicators across family-level sociodemographic gradients as well as country-level indices such as HDI and Gini Index. For example, the International Study of Childhood Obesity, Lifestyle, and the Environment (ISCOLE), ${ }^{136}$ which collected data on 9- to 11-year-old children in 12 countries varying widely on HDI, found opposite relationships between family socioeconomic indicators (ie, income and education) and physical activity and obesity levels ${ }^{16,21,22}$ between HICs and LMICs. Child physical activity levels were higher in higherincome households in HICs but lower in higher-income households in LMICs. ${ }^{21,22}$ Child obesity levels were lower in higher-income households in HICs and higher in higher-income households in LMICs. ${ }^{16,21}$ Clearly there is much to learn from such disparities and inequities and much further to be understood and this should be a priority focus for future comparison initiatives.

\section{Data Gaps and Research Priorities}

The high proportion of incomplete grades (INC), especially for the Active Play and Family and Peers indicators, suggests there is a need for clearer definitions and more thorough data collection methods in most countries. Furthermore, in many countries there is a lack of nationally representative data, and the extent to which inherent biases in existing data distort the true situation is unknown. The collection of data using harmonized measures, including objective measures of physical activity, on larger, more representative samples would improve the validity and reliability of the findings, while also adding greater resolution on within- and between-country differences by sex, age, socioeconomic status, urban/rural living, cultural minorities, children and youth with a disability, and other population stratifications that could help inform future strategies and interventions to improve the grade. Expert recommendations for physical activity surveillance have been published recently in the United States. ${ }^{137}$ Specific future surveillance and research priorities include:

- Expanding the Global Matrix (ie, 3.0) to include even greater global representation (current areas with less representation include the Middle East, South America, Pacific Islands, Caribbean, Russia; see Figure 1)

- Using robust, standardized measures of physical activity and sedentary behaviors on children and youth from countries around the world

- Standardization of interpretation of accelerometer data using agreed upon cut-points for accelerometer types

- Developing a clear accepted definition and valid and reliable measures of active play

- Developing valid and reliable measures of the influence of family and peers on physical activity behaviors of children and youth
- Further prospective multicountry intervention research on the determinants of physical activity and sedentary behaviors in children and youth from countries at different stages of the physical activity transition ${ }^{19}$

- The measurement and surveillance of healthy movement behaviors information (including physical activities of all intensities, sedentary behaviors, and sleep) on young children (toddlers and preschoolers, aged 1 to 5 years) from countries around the world to understand and inform best practices for the promotion of healthy growth and developmental trajectories ${ }^{83}$

- An extension of measures to include emerging health behaviors that have not been typically measured in the past (eg, sitting time, breaks in sitting time, nonscreen time sedentary behaviors, screen time multitasking, emerging screen time subcomponents analyses (eg, texting, Skype), light physical activity) and further research to understand their relationship with health and wellbeing indicators in childhood

- Adding physical fitness as an indicator in future Report Card comparisons

- Further research and surveillance of marginalized groups, including children and youth with a disability, new immigrants and refugees, and rural and remote communities, as well as income and ethnic disparities

- Further evaluation of policies and programs intended to promote physical activity among children and youth, to identify the best and scalable practices, and how they can be best implemented in differing settings

- Cost effectiveness studies of strategies to improve physical activity and sedentary behaviors in children and youth

- Exploration of current surveillance practices at the country level to delineate which variables are over- and under-surveyed (eg, the Scotland 2016 Report Card $^{50}$ revealed over-surveillance of Active Transportation with 4 different national surveys, in contrast to no surveillance of Active Play or Organized Sport Participation).

Unrelated to the Global Matrix 2.0 project, a Delphi survey of international experts established research priorities for child and adolescent physical activity and sedentary behavior, ${ }^{138}$ with the top priorities being development of effective and sustainable interventions to increase long-term physical activity among children and youth; assessment of policy and/or environmental changes and their influence on physical activity and sedentary behaviors of children and youth; and implementation of prospective, longitudinal studies to examine the independent effects of physical activity and sedentary behaviors on health from birth to middle age. ${ }^{138}$

\section{Recommendations for Improving the Grades and Future Directions}

Recommendations to improve the grades were forwarded by country Report Card leaders (coauthors of this paper) and include (presented in random order):

- Promoting and reducing restrictions (eg, over-protectionism) for active play

- Prioritizing the establishment and preservation of safe environments for active play and unstructured physical activity

- Promoting and facilitating safe active transport to school and other destinations 
- Ensuring schools have comprehensive physical activity policies in place that outline ways to encourage and engage students in physical activity throughout the entire school day to promote physical, mental, social, and academic benefits. For example, in addition to formal physical education classes, schools should promote in-class physical activity breaks. This should be developed in consultation with teachers, parents, and students and reviewed over the course of a school year

- Promising and scalable community interventions in public spaces represent an opportunity to promote physical activity in a socially inclusive environment that could contribute to decrease in the unequal access to recreational opportunities, mainly in LMIC. ${ }^{139,140}$ For example, Ciclovías or Open Streets programs, implemented in at least 12 out of the 38 countries participating in the Global Matrix 2.0, are globally recognized as a program to promote physical activity. However, the impact of these programs on children's physical activity levels requires evaluation.

- Improving physical activity and sedentary behavior surveillance by implementing systematic and robust measures (eg, use of objective measures like accelerometry and validated questionnaires) on representative samples across all childhood ages (eg, toddlers through to adolescents)

- Evaluating the implementation, efficacy, and effectiveness of national strategies and policies

- Establishing culturally and geographically (eg, urban vs. rural) appropriate policy interventions and programs

- Ensuring that children, young people, and their families are continually educated on the importance of balancing different types of sedentary behaviors, especially since some are more likely to be detrimental than others (eg, screen time for entertainment vs. study for school vs. reading a book). Parents could use autonomous and supportive parenting practices, whereby they involve children in the formation of household rules and consequences/rewards

- Ensuring the acquisition of fundamental motor skills in early childhood to increase self-efficacy and habitual physical activity

- Encouraging and supporting organized sports clubs to be more inclusive to reduce gender and social inequalities in organized sports participation and also reach the less sports talented.

\section{Strengths and Limitations}

The Global Matrix 2.0 initiative has several strengths, including the $>150 \%$ expansion in the number of participating countries compared with Global Matrix 1.0, the commensurate expansion in the geographical distribution allowing for insights from more genuinely global data, capacity development (see Table 6 for selected quotes from country participants), the clear and transparent identification of data gaps and research needs, the ability to run some statistical comparisons, the facilitation of research collaborations and professional networking, and the formation of a team passionately committed to improving the current and future health and wellbeing of children through increased physical activity.

While the Global Matrix 2.0 represents a significant improvement over the Global Matrix 1.0, ${ }^{15}$ there remain significant limitations and room for improvement. The substantial variation in the quality and quantity of data used to inform the grades between countries remains the greatest limitation to the comparison process. Despite this serious limitation, country leaders believe that the convening of a diverse set of country experts, presented with the collection of the best available data, represents the most authentic and robust method presently available to make such comprehensive comparisons across countries. A recent article examining the correlates of agreement between accelerometry and self-reported physical activity data demonstrated systematic cultural and sociodemographic differences raising questions about the comparability of physical activity data across countries. ${ }^{141}$ This concern, although demonstrated in adults, lends some support to the comprehensive data synthesis approach taken in the development and grading of the Report Cards. ${ }^{12}$ Other limitations of the Global Matrix 2.0 include the lack of inclusion of most of the world's countries; little exploration of disparities and inequities across ability levels, gender, socioeconomic status, or urban vs. rural dwelling; no formal auditing procedure for assigned grades; and lack of clarity on indicator definitions and benchmarks. It is hoped that the Global Matrix 3.0 will show substantial progress toward mitigating these limitations. To this end, country leaders participating in the Global Matrix 2.0 met in Bangkok immediately after the 2016 International Congress on Physical Activity and Public Health to debrief on the experience, expose limitations to within- and between-country comparisons, and discuss potential improvements for the Global Matrix 3.0.

\section{Conclusion}

The Global Matrix 2.0 provides a comprehensive summary of physical activity behavior and sources of influence indicators from 38 countries using a harmonized data gathering, assessing, and grading process. The results suggest a complex network of strengths and limitations across countries, with some global patterns emerging when comparing countries clustered by continent, HDI, ${ }^{62}$ and inequality. ${ }^{63-65}$ There is some evidence of higher physical activity and lower sedentary behavior in countries reporting poorer infrastructure and a greater reliance on Active Play and Active Transportation; and lower physical activity and higher sedentary behavior in countries reporting better infrastructure and a greater reliance on Organized Sport Participation and better School and Community facilities and policies. This paradox suggests autonomy to play and greater independent mobility rather than infrastructure and structured activities may facilitate higher levels of physical activity.

The Global Matrix 2.0 serves as a source of information for researchers, advocates, practitioners, and policy-makers to learn from and build upon. Moreover, the Global Matrix 2.0 is an effective medium for capacity development, especially in LMICs. It facilitates professional networking, cross-fertilization of ideas, conceptualization of strategies and solutions, inception of research collaborations, promotion of advocacy synergy, momentum for change, and inspiration for future work. In the ongoing effort to overcome the persistent and pervasive challenge of increasing childhood physical activity, and to "power the movement to get kids moving," it is recommended that the Global Matrix framework be expanded, improved, and repeated.

\section{Acknowledgments}

The authors would like to acknowledge Active Healthy Kids Canada for developing the Report Card methodology. The authors are indebted to the individual country Research Work Group members and Report Card Project Managers and/or Scientific Officers, including Charlie Vincent 


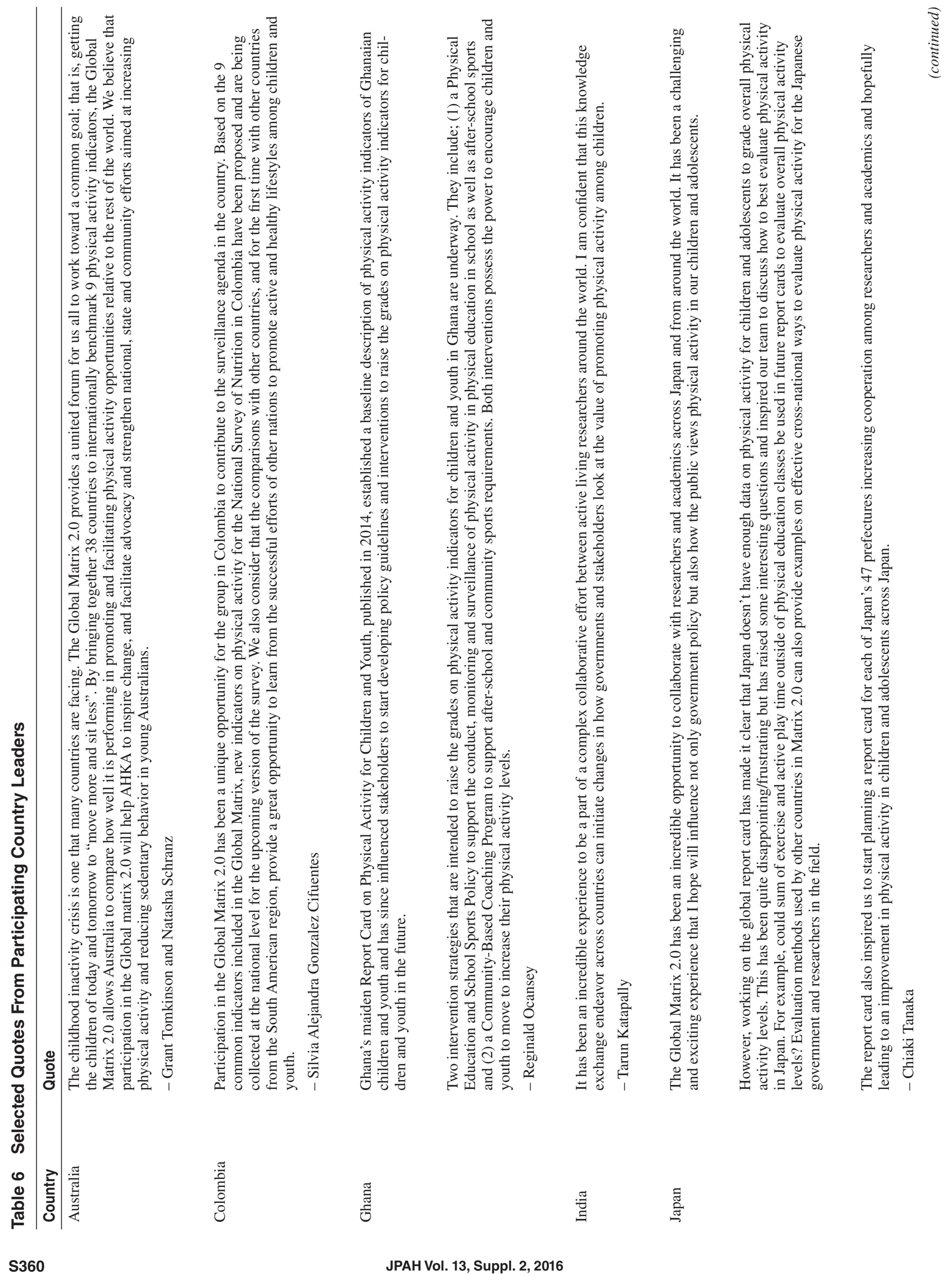




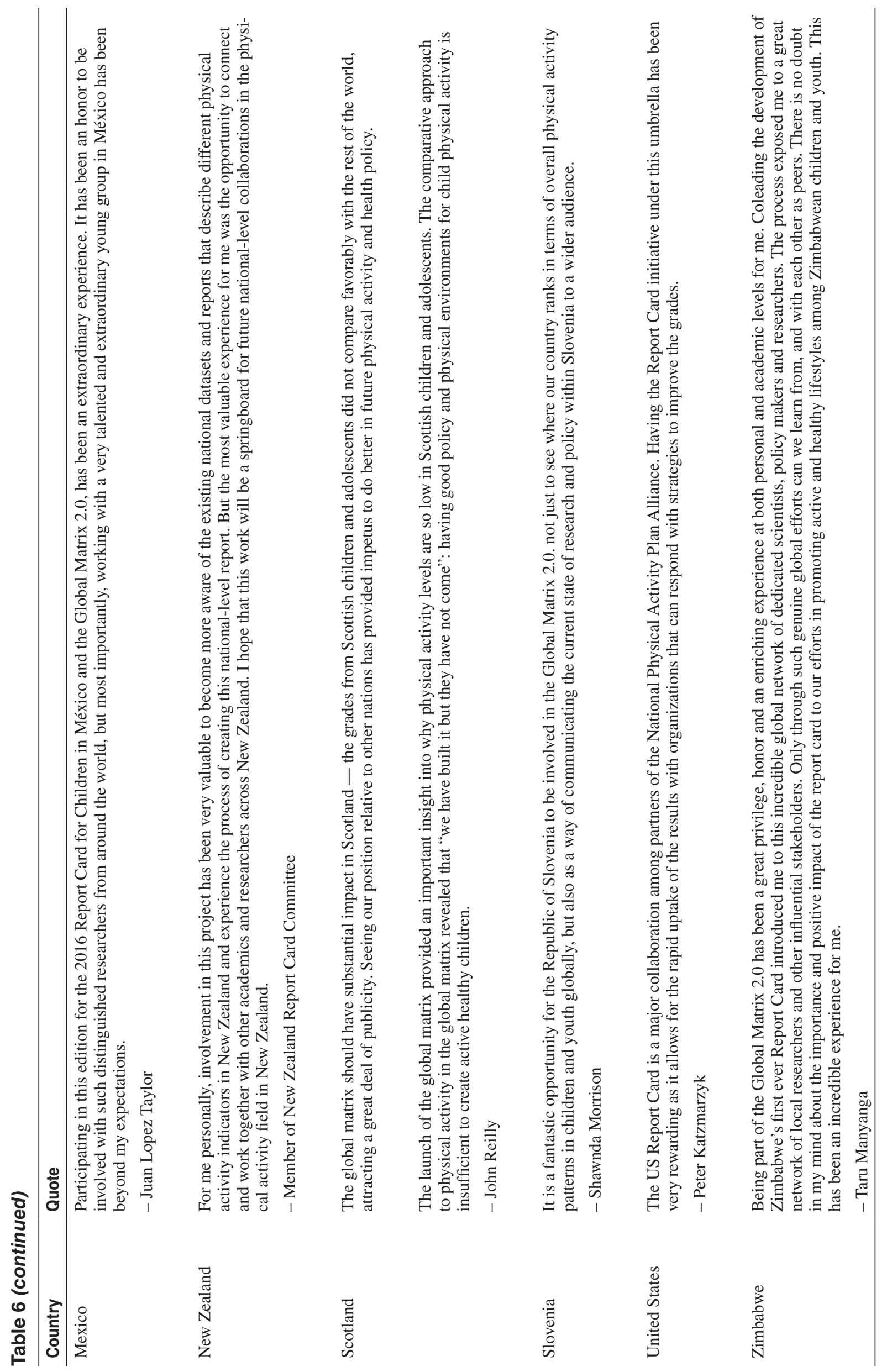


(Australia); Anne I. Wijtzes (Belgium); Allana LeBlanc and Brett Bartlett (Canada); Andrea Cortínez-O'Ryan (Chile); Peijie Chen (China); Olga Lucia Sarmiento (Colombia); Hannah Wilkie (England); Helena Kruusamäe and Merike KullMarcella (Estonia); Katariina Kämppi (Finland); Richmond Aryeetey and Seidu Sofo (Ghana); Deirdre Harrington (Ireland); Stella Muthuri and Sylvester Hayker (Kenya); Karla I. Galaviz (Mexico); Universidade Pedagógica (Mozambique); Marcella Burghard (the Netherlands); Eiman Al-Hammadi (Qatar); Adrienne Hughes (Scotland); Gregor Starc and Vedrana Sember (Slovenia); Monika Uys (South Africa); Lluís Serra-Majem (Spain); Mouza Eid Al Zaabi (United Arab Emirates); Kara Denstel (United States); Betty Méndez-Pérez (Venezuela); Richard Tyler (Wales); Daga Makaza (Zimbabwe). The Hong Kong Report Card was supported by a Knowledge Transfer Fund from the Chinese University of Hong Kong (\#KPF15ICF12). The Thailand Report Card Team thanks the Thai Health Promotion Foundation and Thailand Physical Activity Research Center for their funding and administrative supports.

\section{References}

1. Poitras VJ, Gray CE, Borghese MM, et al. Systematic review of the relationships between objectively measured physical activity and health indicators in school-aged children and youth. Appl Physiol Nutr Metab. 2016;41(6, suppl.3):S197-S239. PubMed doi:10.1139/ apnm-2015-0663

2. Carson V, Hunter S, Kuzik N, et al. Systematic review of sedentary behaviour and health indicators in school-aged children and youth: an update. Appl Physiol Nutr Metab. 2016;41(6, suppl.3):S240-S265. PubMed doi:10.1139/apnm-2015-0630

3. Liu M, Wu L, Yao S. Dose-response association of screen timebased sedentary behaviour in children and adolescents and depression: a meta-analysis of observational studies. Br J Sports Med. 2016;50:1252-1258. PubMed doi:10.1136/bjsports-2015-095084

4. Reis RS, Salvo D, Ogilvie D, Lambert EV, Goenka S, Brownson $\mathrm{RC}$, for the Lancet Physical Activity Series 2 Executive Committee. Scaling up physical activity interventions worldwide: stepping up to larger and smarter approached to get people moving. Lancet. 2016; published online July 27.

5. Ding D, Lawson KD, Kolbe-Alexander TL, et al. for the Lancet Physical Activity Series 2 Executive Committee. The economic burden of physical inactivity: a global analysis of major non-communicable diseases. Lancet. 2016; published online July 27.

6. World Health Organization. Report of the Commission on Ending Childhood Obesity. Geneva: World Health Organization; 2016.

7. Inchley J, Currie D, Young T, et al, eds. Health Policy for Children and Adolescents No. 7. Growing up unequal: gender and socioeconomic differences in young people's health and well-being. Health Behaviour in School-aged Children Study: International Report from the 2013/2014 Survey. Geneva: World Health Organization Regional Office for Europe; 2016.

8. Katzmarzyk PT, Barreira TV, Broyles ST, et al for the ISCOLE Research Group. Physical activity, sedentary time and obesity in an international sample of children. Med Sci Sports Exerc. 2015;47:20622069. PubMed doi:10.1249/MSS.0000000000000649

9. World Health Organization Regional Office for Europe. Physical activity strategy for the WHO European Region 2016-2025. Regional Committee for Europe, September, 2015.

10. Sallis JF, Bull F, Guthold R, et al. for the Lancet Physical Activity Series 2 Executive Committee. Progress in physical activity over the Olympic quadrennium. Lancet 2016; published online July 27.

11. Barnes J, Tremblay MS. Changes in indicators of child and youth physical activity in Canada, 2005-2016. Can J Public Health, in press.
12. Colley RC, Brownrigg M, Tremblay MS. The Active Healthy Kids Canada Report Card on Physical Activity for Children and Youth. Health Promot Pract. 2012;13(3):320-330. PubMed doi:10.1177/1524839911432929

13. Tremblay MS, Barnes JD, Cowie Bonne J. Impact of the Active Healthy Kids Canada Report Card: A 10-year analysis. J Phys Act Health. 2014;11(suppl.1):S3-S20. PubMed doi:10.1123/jpah.2014-0167

14. Tremblay MS. 2014 Global Summit on the Physical Activity of Children. J Phys Act Health. 2014;11(suppl.1):S1-S2. PubMed doi:10.1123/jpah.2014-0182

15. Tremblay MS, Gray CE, Akinroye K, et al. Physical activity of children: a global matrix of grades comparing 15 countries related to the physical activity of children. J Phys Act Health. 2014;11(Suppl. 1):S113-S125. PubMed doi:10.1123/jpah.2014-0177

16. Broyles ST, Denstel KD, Church TS, et al. The epidemiological transition and the global childhood obesity epidemic. Int J Obes Suppl. 2015;5:S3-S8. PubMed doi:10.1038/ijosup.2015.12

17. Atkinson K, Lowe S, Moore S. Human development, occupational structure and physical inactivity among 47 low and middle income countries. Prev Med Rep. 2016;3:40-45. PubMed doi:10.1016/j. pmedr.2015.11.009

18. Omran AR. The epidemiologic transition. A theory of the epidemiology of population change. Milbank Mem Fund Q. 1971;49:509-538. PubMed doi:10.2307/3349375

19. Katzmarzyk PT, Mason C. The physical activity transition. J Phys Act Health. 2009;6:269-280. PubMed doi:10.1123/jpah.6.3.269

20. Muthuri SK, Wachira LJM, LeBlanc AG, et al. Temporal trends and correlates of physical activity, sedentary behaviour, and physical fitness among school-aged children in sub-Saharan Africa: a systematic review. Int J Environ Res Public Health. 2014;11:3327-3359. PubMed doi:10.3390/ijerph110303327

21. Katzmarzyk PT, Barreira TV, Broyles ST, et al. Relationship between lifestyle behaviours and obesity in 9-11 year old children: Results from a 12-country study. Obesity (Silver Spring). 2015;23:1696-1702. PubMed doi:10.1002/oby.21152

22. Katzmarzyk PT, Barreira TV, Broyles ST, et al. Physical activity, sedentary time and obesity in an international sample of children. Med Sci Sports Exerc. 2015;47:2062-2069. PubMed doi:10.1249/ MSS.0000000000000649

23. Tremblay MS, Barnes JD, Gonzalez SA, Katzmarzyk PT, Onywera VO, Reilly JJ, Tomkinson G. Introduction to the Global Matrix 2.0: Report Card Grades on the Physical Activity of Children and Youth Comparing 38 Countries. J Phys Act Health. 2016;13(Suppl 2):S85S86.

24. Schranz N, Olds T, Boyd R, et al. Results from Australia's 2016 Report Card on Physical Activity for Children and Youth. J Phys Act Health. 2016;13(Suppl 2):S87-S94.

25. Wijtzes AI, Verloigne M, Mouton A, et al. Results from Belgium's 2016 Report Card on Physical Activity for Children and Youth. J Phys Act Health. 2016;13(Suppl 2):S95-S103.

26. Nardo N, Junior, Silva DAS, Ferrari GLM, et al. Results from Brazil's 2016 Report Card on Physical Activity for Children and Youth. J Phys Act Health. 2016;13(Suppl 2):S104-S109.

27. Barnes J, Cameron C, Carson V, et al. Results from Canada's 2016 ParticipACTION Report Card on Physical Activity for Children and Youth. J Phys Act Health. 2016;13(Suppl 2):S110-S116.

28. Aguilar-Farias N, Cortinez-O'Ryan A, Sadarangani KP, et al. Results from Chile's 2016 Report Card on Physical Activity for Children and Youth. J Phys Act Health. 2016;13(Suppl 2):S117-S123.

29. Liu Y, Tang Y, Cao ZB, et al. Results From Shanghai's (China) 2016 Report Card on Physical Activity for Children and Youth. J Phys Act Health. 2016;13(Suppl 2):S124-S128. 
30. González SA, Castiblanco MA, Arias-Gómez LF, et al. Results from Colombia's 2016 Report Card on Physical Activity for Children and Youth. J Phys Act Health. 2016;13(Suppl 2):S129S136.

31. Larsen LR, Troelsen J, Kirkegaard KL, et al. Results from Denmark's 2016 Report Card on Physical Activity for Children and Youth. J Phys Act Health. 2016;13(Suppl 2):S137-S142.

32. Wilkie H, Standage M, Sherar L, et al. Results from England's 2016 Report Card on Physical Activity for Children and Youth. J Phys Act Health. 2016;13(Suppl 2):S143-S149.

33. Kruusamäe H, Kull M, Mooses K, Riso EM, Jürimäe J. Results from Estonia's 2016 Report Card on Physical Activity for Children and Youth. J Phys Act Health. 2016;13(Suppl 2):S150-S156.

34. Tammelin T, Aira A, Hakamäki M, et al. Results from Finland's 2016 Report Card on Physical Activity for Children and Youth. J Phys Act Health. 2016;13(Suppl 2):S157-S164.

35. Ocansey R, Aryeetey R, Sofo S, et al. Results from Ghana's 2016 Report Card on Physical Activity for Children and Youth. J Phys Act Health. 2016;13(Suppl 2):S165-S168.

36. Wong SH, Huang WY, Wong MC, Sit CH, Sum RK, He G. Results from Hong Kong's 2016 Report Card on Physical Activity for Children and Youth. J Phys Act Health. 2016;13(Suppl 2):S169-S175.

37. Katapally TR, Goenka S, Bhawra J, et al. Results from India 2016 Report Card on Physical Activity for Children and Youth. J Phys Act Health. 2016;13(Suppl 2):S176-S187.

38. Harrington DM, Murphy M, Carlin A, et al. Results From Ireland North and South's 2016 Report Card on Physical Activity for Children and Youth. J Phys Act Health. 2016;13(Suppl 2):S183S188.

39. Tanaka C, Tanaka S, Inoue S, Miyachi M, Suzuki K, Reilly JJ. Results from Japan's 2016 Report Card on Physical Activity for Children and Youth. J Phys Act Health. 2016;13(Suppl 2):S189-S194.

40. Onywera VO, Muthuri SK, Hayker S, et al. Results From Kenya's 2016 Report Card on Physical Activity for Children and Youth. J Phys Act Health. 2016;13(Suppl 2):S195-S200.

41. Sharif R, Chong KH, Zakaria NH, et al. Results from Malaysia's 2016 Report Card on Physical Activity for Children and Adolescents. J Phys Act Health. 2016;13(Suppl 2):S201-S205.

42. Galaviz KI, Aguilar Arroyo M, González-Casanova I, et al. Results from Mexico's 2016 Report Card on Physical Activity for Children and Youth. J Phys Act Health. 2016;13(Suppl 2):S206-S212.

43. Prista A, Daca T, Tchonga F, Machava E, Macucule C, Ribeiro E. Results from Mozambique's 2016 Report Card on Physical Activity for Children and Adolescents. J Phys Act Health. 2016;13(Suppl 2):S213-S217.

44. Burghard M, Knitel K, van Oost I, Tremblay MS, Takken T, on behalf of the Dutch Physical Activity Report Card Study Group. Is our youth cycling to health? Results from the Netherland's 2016 Report Card on Physical Activity for Children and Youth. J Phys Act Health. 2016;13(Suppl 2):S218-S224.

45. Maddison R, Marsh S, Hinckson E, et al. Results from New Zealand's 2016 Report Card on Physical Activity for Children and Youth. J Phys Act Health. 2016;13(Suppl 2):S225-S230.

46. Adeniyi AF, Odukoya OO, Oyeyemi AL, et al. Results from Nigeria's 2016 Report Card on Physical Activity for Children and Youth. J Phys Act Health. 2016;13(Suppl 2):S231-S236.

47. Goldys A, Nałęcz H, Zembura P. Results from Poland's 2016 Report Card on Physical Activity for Children and Youth. J Phys Act Health. 2016;13(Suppl 2):S237-S241.

48. Mota J, Coelho e Silva MJ, Raimundo AM, Sardinha LB. Results from Portugal's 2016 Report Card on Physical Activity for Children and Youth. J Phys Act Health. 2016;13(Suppl 2):S242-S245.
49. Al-Kuwari MG, Ibrahim IA, Al Hammadi EM, Reilly JJ. Results from Qatar's 2016 Active Healthy Kids Report Card. J Phys Act Health. 2016;13(Suppl 2):S246-S250.

50. Reilly JJ, Johnstone A, McNeill G, Hughes AR. Results from Scotland's 2016 Report Card on Physical Activity for Children and Youth. J Phys Act Health. 2016;13(Suppl 2):S251-S255.

51. Sember V, Starc G, Jurak G, et al. Results from the Republic of Slovenia's 2016 Report Card on Physical Activity for Children and Youth. J Phys Act Health. 2016;13(Suppl 2):S256-S264.

52. Uys M, Bassett S, Draper CE, . . . and the HAKSA 2016 Writing Group. Results from South Africa's 2016 Report Card on Physical Activity for Children and Youth. J Phys Act Health. 2016;13(Suppl 2):S265-S273.

53. Song Y, Yang H, Lee E, et al. Results from South Korea's 2016 Report Card on Physical Activity for Children and Youth. J Phys Act Health. 2016;13(Suppl 2):S274-S278.

54. Roman-Viñas B, Marin J, Sánchez-López M, et al. Results from Spain's 2016 Report Card on Physical Activity for Children and Youth. J Phys Act Health. 2016;13(Suppl 2):S279-S283.

55. Delisle-Nystrom C, Larsson C, Ehrenblad B, et al. Results from Sweden's 2016 Report Card on Physical Activity for Children and Youth. J Phys Act Health. 2016;13(Suppl 2):S284-S290.

56. Amornsriwatanakul A, Nakornkate K, Katewongsa P, et al. Results from Thailand's 2016 Report Card on Physical Activity for Children and Youth. J Phys Act Health. 2016;13(Suppl 2):S291-S298.

57. Al Zaabi M, Shah SM, Sheek-Hussein M, Abdulle A, Al Junaibi A, Loney T. Results from the United Arab Emirates' 2016 Report Card on Physical Activity for Children and Youth. J Phys Act Health. 2016;13(Suppl 2):S299-S306.

58. Katzmarzyk PT, Denstel KD, Beals K, et al. Results from the United States of America's 2016 Report Card on Physical Activity for Children and Youth. J Phys Act Health. 2016;13(Suppl 2):S307-S313.

59. Herrera-Cuenca M, Méndez-Perez B, Castro Morales V, et al. Results from Venezuela's 2016 Report Card on Physical Activity for Children and Youth. J Phys Act Health. 2016;13(Suppl 2):S314-S329.

60. Tyler R, Mannello M, Mattingley R, et al. Results from the Active Healthy Kids Wales 2016 Report Card on Physical Activity for Children and Youth. J Phys Act Health. 2016;13(Suppl 2):S330-S336.

61. Manyanga T, Makaza D, Mahachi C, et al. Results from Zimbabwe's 2016 Report Card on the Physical Activity of Children and Youth. $J$ Phys Act Health. 2016;13(Suppl 2):S337-S342.

62. United Nations Development Programme. Human Development Index (HDI). New York: United Nations Development Programme. hdr. undp.org/en/content/human-development-index-hdi. Accessed July 28, 2016.

63. The World Bank. Gini index (World Bank estimate). Washington: The World Bank. data.worldbank.org/indicator/SI.POV.GINI?view=map. Accessed July 28, 2016.

64. United Nations Development Programme. Gender Inequality Index (GII). New York: United Nations Development Programme. hdr.undp. org/en/content/gender-inequality-index-gii. Accessed July 28, 2016.

65. United Nations Development Programme. Composite indices - HDI and beyond. New York: United Nations Development Programme. hdr. undp.org/en/statistics/understanding/indices. Accessed July 28, 2016.

66. Economist Intelligence Unit. Global Food Security Index. London: Economist Intelligence Unit. foodsecurityindex.eiu.com. Accessed July 28, 2016.

67. Wikimedia Foundation. All-time Olympic Games medal table. San Francisco: Wikimedia Foundation. en.wikipedia.org/wiki/All-time_ Olympic_Games_medal_table. Accessed July 28, 2016.

68. GMT. Countries Latitudes and Longitudes. www.gmttimedate.com/ countrylatlong. Accessed July 28, 2016. 
69. National Hurricane Center. Latitude/Longitude Distance Calculator. Miami: National Hurricane Center. URL: www.nhc.noaa.gov/gecalc. shtml. Accessed July 28, 2016.

70. Hallal PC, Andersen LB, Bull FC, Guthold R, Haskell W, Ekelund U. Global physical activity levels: surveillance progress, pitfalls, and prospects. Lancet. 2012;380(9838):230-240. PubMed doi:10.1016/ S0140-6736(12)60646-1

71. Strel J. Analiza programa »Zdrav življenjski slog « za leti 2010/11 in 2011/12. Ljubljana: Institute for Sport Planica; 2013. [Analysis of the program Healthy Lifestyle for the years 2010/11 and 2011/12].

72. Katzmarzyk PT, Tremblay MS. Limitations of Canada's physical activity data: implications for monitoring trends. Appl Physiol Nutr Metab. 2007;32(suppl.2E):S185-S194. PubMed doi:10.1139/H07-113

73. Ekelund U, Tomkinson GR, Armstrong N. What proportion of youth are physically active? Measurement issues, levels and recent time trends. Br J Sports Med. 2011;45:859-865. PubMed doi:10.1136/ bjsports-2011-090190

74. Ashley R, Cooper AR, Goodman A, et al. Objectively measured physical activity and sedentary time in youth: the International children's accelerometry database (ICAD). Int J Behav Nutr Phys Act. 2015;12:113. PubMed doi:10.1186/s12966-015-0274-5

75. Lang JJ, Tremblay MS, Leger L, Olds T, Tomkinson GR. International variability in $20 \mathrm{~m}$ shuttle run performance in children and youth: who are the fittest from a 50-country comparison? A systematic literature review with pooling of aggregate results. Br J Sports Med, in press. PubMed

76. Muthuri SK, Wachira LJM, LeBlanc AG, et al. Temporal trends and correlates of physical activity, sedentary behaviour, and physical fitness among school-aged children in Sub-Saharan Africa: a systematic review. Int J Environ Res Public Health. 2014;11:3327-3359. PubMed doi:10.3390/ijerph110303327

77. Particip ACTION. The Biggest Risk is Keeping Kids Indoors. 2015 Report Card in the Physical Activity of Children and Youth. ParticipACTION; 2015.

78. Tremblay MS, Gray C, Babcock S, et al. Position statement on active outdoor play. Int J Environ Res Public Health. 2015;12:6475-6505. PubMed doi:10.3390/ijerph120606475

79. Gray C, Gibbons R, Larouche R, et al. What is the relationship between outdoor time and physical activity, sedentary behaviour, and physical fitness in in children? A systematic review. Int J Environ Res Public Health. 2015;12:6455-6474. PubMed doi:10.3390/ijerph120606455

80. Brussoni M, Gibbons R, Gray C, et al. What is the relationship between risky outdoor play and health in children? A systematic review. Int J Environ Res Public Health. 2015;12:6423-6454. PubMed doi:10.3390/ijerph120606423

81. Larouche R, Garriguet D, Gunnell K, Goldfield G, Tremblay MS. Outdoor time, physical activity and health-related indicators among children: the 2012-2013 Canadian Health Measures Survey. Health Rep. 2016;27(9):3-13. PubMed

82. Cooper AR, Page AS, Wheeler BW, Hillsdon M, Griew P, Jago R. Patterns of GPS measured time outdoors after school and objective physical activity in English children: the PEACH project. Int J Behav Nutr Phys Act. 2010;7:31. PubMed doi:10.1186/1479-5868-7-31

83. World Health Organization. Report of the Commission on Ending Childhood Obesity. Geneva: World Health Organization; 2016.

84. Tremblay MS, Carson V, Chaput J-P, et al. Canadian 24-hour Movement Guidelines for Children and Youth: An Integration of Physical Activity, Sedentary Behaviour, and Sleep. Appl Physiol Nutr Metab. 2016;41(6, suppl.3):S311-S327. PubMed doi:10.1139/apnm-20160151

85. United Nations. Convention on the Rights of the Child. General Assembly of the United Nations; 1989.
86. Tremblay MS, Onywera V, Adamo KB. A child's right to healthy active living - Building capacity in Sub-Saharan Africa to curb the impending physical activity transition: The KIDS-CAN Research Alliance. In S. Bennett and M. Pare (Eds.) 20th Anniversary of the Convention on the Rights of the Child, University of Ottawa Press, p. 97-110, 2010.

87. Colley RC, Garriguet D, Janssen I, Craig CL, Clarke J, Tremblay MS. Physical activity of Canadian children and youth: accelerometer results from the 2007 to 2009 Canadian Health Measures Survey. Health Rep. 2011;22(1):15-24. PubMed

88. Tremblay MS, Colley R, Saunders TJ, Healy GN, Owen N. Physiological and health implications of a sedentary lifestyle. Appl Physiol Nutr Metab. 2010;35:725-740. PubMed doi:10.1139/H10-079

89. Salvo D, Reis RS, Sarmiento OL, Pratt M. Overcoming the challenges of conducting physical activity and built environment research in Latin America: IPEN Latin America. Prev Med. 2014;69:S86-S92. PubMed doi:10.1016/j.ypmed.2014.10.014

90. Sarmiento OL, Lemoine PD, Gonzalez SA, et al. Relationships between active school transport and adiposity indicators in school age children from low-, middle- and high-income countries. Int J Obes. 2015;5:S107-S114. PubMed

91. Larouche R, Saunders TJ, Faulkner GEJ, Colley RC, Tremblay MS. Associations between active school transport and physical activity, body composition and cardiovascular fitness: a systematic review of 68 studies. J Phys Act Health. 2014;11:206-211. PubMed doi:10.1123/ jpah.2011-0345

92. Active Healthy Kids Canada. Are We Driving Our Kids to Unhealthy Habits? The 2013 Active Healthy Kids Canada Report Card on Physical Activity for Children and Youth. Toronto: Active Healthy Kids Canada; 2013.

93. McDonald NC. Active transportation to school: trends among U.S. schoolchildren, 1969-2001. Am J Prev Med. 2007;32:509-516. PubMed doi:10.1016/j.amepre.2007.02.022

94. Pabayo R, Gauvin L, Barnett TA. Longitudinal changes in active transportation to school in Canadian children aged 6 through 16 years. Pediatrics. 2011;128(2):e404-e413. PubMed doi:10.1542/peds.20101612

95. Lewis N, Dollman J, Dale M. Trends in physical activity behaviours and attitudes among South Australian youth between 1985 and 2004. J Sci Med Sport. 2007;10(6):418-427. PubMed doi:10.1016/j. jsams.2006.10.005

96. van der Ploeg HP, Merom D, Corpuz G, Bauman AE. Trends in Australian children travelling to school 1971-2003: burning petrol or carbohydrates? Prev Med. 2008;46(1):60-62. PubMed doi:10.1016/j. ypmed.2007.06.002

97. Costa F, Silva K, Schmoelz C, Campos V, de Assis M. Longitudinal and cross-sectional changes in active commuting to school among Brazilian schoolchildren. Prev Med. 2012;55(3):212-215. PubMed doi:10.1016/j.ypmed.2012.06.023

98. Transport Scotland. Scottish transport statistics No. 32, 2013. www. transportscotland.gov.uk/strategy-and-research/publications-andconsultations/j285663-00.htm. Accessed March 5, 2014.

99. Ham S, Martin S, Kohl H, III. Changes in the percentage of students who walk or bike to school - United States, 1969 and 2001. J Phys Act Health. 2008;5(2):205-215. PubMed doi:10.1123/jpah.5.2.205

100. McDonald N, Brown A, Marchetti L, Pedroso MUS. School travel, 2009: an assessment of trends'. Am J Prev Med. 2011;41(2):146-151. PubMed doi:10.1016/j.amepre.2011.04.006

101. Onywera V, Adamo KB, Sheel AW, Waudo J, Boit M, Tremblay MS. Emerging evidence of the physical activity transition in Kenya. $J$ Phys Act Health. 2012;9:554-562. PubMed doi:10.1123/jpah.9.4.554

102. Stone MR, Mammen G, Faulkner G. Canadian School Travel Planning Intervention Results (National Report). (2010-12). Canadian 
Partnership Against Cancer, Coalitions Linking Action and Science for Prevention (CLASP) initiative, and Green Communities Canada; 2012.

103. Shaw B, Watson B, Frauendienst B, Redecker A, Jones T, Hillman M. Children's Independent Mobility: A Comparative Study in England and Germany (1971-2010). London: Policy Studies Institute; 2013.

104. Tremblay MS, Esliger DW, Copeland JL, Barnes JD, Bassett DR. Moving forward by looking back: lessons learned from lost lifestyles. Appl Physiol Nutr Metab. 2008;33:836-842. PubMed doi:10.1139/ H08-045

105. Government of Australia, Department of Health. Australia's Physical Activity and Sedentary Behaviour Guidelines - 5-12 years. Commonwealth of Australia; 2014.

106. Tremblay MS, LeBlanc AG, Janssen I, et al. Canadian sedentary behaviour guidelines for school-aged children and youth. Appl Physiol Nutr Metab. 2011;36(1):59-64. PubMed doi:10.1139/H11-012

107. Lear SA, Teo K, Gasevic D, et al. The association between ownership of common household devices and obesity and diabetes in high, middle and low income countries. CMAJ. 2014;186:258-266. PubMed doi:10.1503/cmaj.131090

108. IKEA. Playreport: international summary research results. 2010. www. slideshare.net/dinomondon/ikea-playreport-international-summary. Accessed June 22, 2016.

109. Salmon J, Tremblay MS, Marshall SJ, Hume C. Health risks, correlates and interventions to reduce sedentary behavior in young people. Am J Prev Med. 2011;41(2):197-206. PubMed doi:10.1016/j. amepre.2011.05.001

110. Tremblay MS, LeBlanc AG, Carson V, et al. Canadian sedentary behaviour guidelines for the early years (aged 0-4 years). Appl Physiol Nutr Metab. 2012;37:370-380. PubMed doi:10.1139/h2012-019

111. Active S. Stay Active. A Report on Physical Activity for Health from the Four Home Countries' Chief Medical Officers. England: Department of Health; 2011.

112. Okely AD, Salmon J, Vella SA, et al. A Systematic Review to inform the Australian Sedentary Behaviour Guidelines for Children and Young People. Report prepared for the Australian Government Department of Health, June 2012.

113. Government of Australia, Department of Health. Australia's Physical Activity and Sedentary Behaviour Guidelines - 13-17 years. Commonwealth of Australia, 2014.

114. Sedentary Behaviour Research Network. Letter to the Editor: Standardized use of the terms "sedentary" and "sedentary behaviours". Appl Physiol Nutr Metab. 2012;37(3):540-542.

115. Maitland C, Stratton G, Foster S, Braham R, Rosenberg M. A place for play? The influence of the home physical environment on children's physical activity and sedentary behaviour. Int J Behav Nutr Phys Act. 2013;10:99. PubMed doi:10.1186/1479-5868-10-99

116. Atkin AJ, Corder K, Ekelund U, Wijndaele K, Griffin SJ, van Sluijs EM. Determinants of change in children's sedentary time. PLoS One. 2013;8(6):e67627. PubMed doi:10.1371/journal.pone.0067627

117. McMinn AM, Griffin SJ, Jones AP, van Sluijs EM. Family and home influences on children's after-school and weekend physical activity. Eur J Public Health. 2012;23(5):805-810. PubMed doi:10.1093/ eurpub/cks160

118. Maturo CC, Cunningham SA. Influence of friends on children's physical activity: a review. Am J Public Health. 2013;103(7):e23-e38. PubMed doi:10.2105/AJPH.2013.301366

119. Canadian Fitness and Lifestyle Research Institute. 2010-11 Physical Activity Monitor. Bulletin 5: Parental involvement in child's physical activity and sport. Ottawa: Canadian Fitness and Lifestyle Research Institute; 2013. www.cflri.ca/node/1180. Accessed August 10, 2016.
120. Fuemmeler BF, Anderson CB, Masse LC. Parent-child relationship of directly measured physical activity. Int J Behav Nutr Phys Act. 2011;8:17. PubMed doi:10.1186/1479-5868-8-17

121. Tucker P, van Zandvoort MM, Burke SM, Irwin JD. The influence of parents and the home environment on preschoolers' physical activity behaviours: a qualitative investigation of childcare providers' perspectives. BMC Public Health. 2011;11:168. PubMed doi:10.1186/14712458-11-168

122. Abbott G, Hnatiuk J, Timperio A, Salmon J, Best K, Hesketh KD. Cross-sectional and longitudinal associations between parents' and preschoolers' physical activity and television viewing: The HAPPY Study. J Phys Act Health. 2016;13:269-274. PubMed doi:10.1123/ jpah.2015-0136

123. European Commission/EACEA/Eurydice. Physical Education and Sport at School in Europe Eurydice Report. Luxembourg: Publications Office of the European Union; 2013.

124. Pühse U, Gerber M (Eds). International Comparison of Physical Education: Concepts, Problems, Prospects. Oxford: Meyer \& Meyer Sport (UK) Ltd.; 2005.

125. Lowry R, Brener N, Lee S, Epping J. Participation in high school physical education-United States, 1991-2003. MMWR. 2004;53(36):844847. PubMed

126. UNESCO. Quality Physical Education (QPE) Guidelines for Policy Makers. Paris: United Nations Educational, Scientific and Cultural Organization; 2015.

127. Salmon J, Timperio A, Cleland V, Venn A. Trends in children's physical activity and weight status in high and low socio-economic status areas of Melbourne, Victoria, 1985-2001. Aust N Z J Public Health. 2005;29(4):337-342. PubMed doi:10.1111/j.1467-842X.2005. tb00204.x

128. Yli-Piipari S, Kulmala JS, Jaakkola T, Hakonen H, Fish JC, Tammelin T. Objectively measured school day physical activity among elementary students in the United States and Finland. J Phys Act Health. 2016;13:440-446. PubMed doi:10.1123/jpah.2015-0335

129. Government of Australia, Department of Health. Australia's Physical Activity and Sedentary Behaviour Guidelines - 5-12 years. Commonwealth of Australia; 2014.

130. Giles-Corti B, Vernez-Moudon A, Reis R, et al. City planning and population health: a global challenge. Lancet 2016 Sep 19. pii: S0140-6736(16)30066-6. doi:10.1016/S0140-6736(16)30066-6. [Epub ahead of print].

131. Adams MA, Ding D, Sallis JF, et al. Patterns of neighborhood environment attributes related to physical activity across 11 countries: a latent class analysis. Int J Behav Nutr Phys Act. 2013;10:34. PubMed doi:10.1186/1479-5868-10-34

132. Sallis JF, Cerin E, Conway TL, et al. Physical activity in relation to urban environments in 14 cities worldwide: a cross-sectional study. Lancet. 2016;387(10034):2207-2217. PubMed doi:10.1016/S01406736(15)01284-2

133. Davison KK, Lawson CT. Do attributes in the physical environment influence children's physical activity? A review of the literature. Int J Behav Nutr Phys Act. 2006;3(1):1. PubMed doi:10.1186/14795868-3-1

134. Murray CJL, Lopez AD. Global mortality, disability, and the contribution of risk factors: global burden of disease study. Lancet. 1997;349:1436-1442. PubMed doi:10.1016/S0140-6736(96)07495-8

135. Maulik PK, Darmstadt GL. Childhood disability in low- and middleincome countries: overview of screening, prevention, services, legislation, and epidemiology. Pediatrics. 2007;120(suppl.1):S1-S55. PubMed doi:10.1542/peds.2007-0043B

136. Katzmarzyk PT, Barreira TV, Broyles ST, et al. The International Study of Childhood Obesity, Lifestyle and the Environment (ISCOLE): 
design and methods. BMC Public Health. 2013;13:900. PubMed doi:10.1186/1471-2458-13-900

137. Fulton JE, Carlson SA, Ainsworth BE, et al. Strategic priorities for physical activity surveillance in the United States. Med Sci Sports Exerc. 2016;48:2057-2069. PubMed doi:10.1249/ MSS.0000000000000989

138. Gillis L, Tomkinson G, Olds T, et al. Research priorities for child and adolescent physical activity and sedentary behaviours: a global perspective using a twin-panel Delphi procedure. Int J Behav Nutr Phys Act. 2013;10:112. PubMed doi:10.1186/1479-5868-10-112

139. Sarmiento O, Díaz del Castillo A, Triana CA, Acevedo MJ, Gonzalez SA, Pratt M. Reclaiming the streets for people: insights from Ciclovias
Recreativas in Latin America. Prev Med. 2016, in press. PubMed doi:10.1016/j.ypmed.2016.07.028

140. Díaz del Castillo A, González SA, Ríos AP, et al. Start small, dream big: experiences of physical activity in public spaces in Colombia. Prev Med. 2016, in press. PubMed doi:10.1016/j.ypmed.2016.08.028

141. Cerin E, Cain KL, Oyeyemi AL, et al. Correlates of agreement between accelerometry and self-reported physical activity. Med Sci Sports Exerc. 2016;48:1075-1084. PubMed doi:10.1249/ MSS.0000000000000870 